\title{
Interpretation of FRESCO cloud retrievals in case of absorbing aerosol events
}

\author{
P. Wang, O. N. E. Tuinder, L. G. Tilstra, M. de Graaf, and P. Stammes \\ Royal Netherlands Meteorological Institute (KNMI), De Bilt, The Netherlands \\ Correspondence to: P. Wang (wangp@knmi.nl) \\ Received: 17 October 2011 - Published in Atmos. Chem. Phys. Discuss.: 12 December 2011 \\ Revised: 18 July 2012 - Accepted: 19 September 2012 - Published: 4 October 2012
}

\begin{abstract}
Cloud and aerosol information is needed in trace gas retrievals from satellite measurements. The Fast REtrieval Scheme for Clouds from the Oxygen A band (FRESCO) cloud algorithm employs reflectance spectra of the $\mathrm{O}_{2} \mathrm{~A}$ band around $760 \mathrm{~nm}$ to derive cloud pressure and effective cloud fraction. In general, clouds contribute more to the $\mathrm{O}_{2} \mathrm{~A}$ band reflectance than aerosols. Therefore, the FRESCO algorithm does not correct for aerosol effects in the retrievals and attributes the retrieved cloud information entirely to the presence of clouds, and not to aerosols. For events with high aerosol loading, aerosols may have a dominant effect, especially for almost cloud free scenes. We have analysed FRESCO cloud data and Absorbing Aerosol Index (AAI) data from the Global Ozone Monitoring Experiment (GOME-2) instrument on the Metop-A satellite for events with typical absorbing aerosol types, such as volcanic ash, desert dust and smoke. We find that the FRESCO effective cloud fractions are correlated with the AAI data for these absorbing aerosol events and that the FRESCO cloud pressure contains information on aerosol layer pressure. For cloud free scenes, the derived FRESCO cloud pressure is close to the aerosol layer pressure, especially for optically thick aerosol layers. For cloudy scenes, if the strongly absorbing aerosols are located above the clouds, then the retrieved FRESCO cloud pressure may represent the height of the aerosol layer rather than the height of the clouds. Combining FRESCO and AAI data, an estimate for the aerosol layer pressure can be given.
\end{abstract}

\section{Introduction}

Cloud and aerosol information is relevant for the trace gas retrievals from satellite spectrometers like the Scanning Imaging Absorption Spectrometer for Atmospheric CHartographY (SCIAMACHY) on Envisat (Bovensmann et al., 1999) and the Global Ozone Monitoring Experiment (GOME-2) on Metop-A (Munro et al., 2006). Cloud products are used to screen cloudy pixels or to correct for the effects of clouds on the trace gas retrievals. Various algorithms have been developed to retrieve cloud parameters from the SCIAMACHY and GOME-2 oxygen A band spectral measurements (e.g. Koelemeijer et al., 2001; Kokhanovsky et al., 2006) and from the PMD (Polarisation Measurement Device) imagery measurements (Loyola, 2004; Grzegorski et al., 2006).

The Fast Retrieval Scheme for Clouds from the Oxygen A band (FRESCO) cloud retrieval algorithm has been developed as a simple but fast and robust algorithm for GOME, SCIAMACHY and GOME-2 (Koelemeijer et al., 2001; Wang et al., 2008). FRESCO employs the reflectance spectrum of the $\mathrm{O}_{2} \mathrm{~A}$ band at $760 \mathrm{~nm}$ to derive effective cloud fraction and cloud pressure. Aerosols are treated in the same way as clouds in FRESCO, because clouds have much larger effects on the $\mathrm{O}_{2} \mathrm{~A}$ band reflectances than aerosols in cloudy scenes. FRESCO cloud pressures have been validated with ground-based lidar/radar measurements (Wang et al., 2008). The FRESCO cloud product has not been investigated for events with high aerosol loading. It is well-known that the $\mathrm{O}_{2}$ A band is suitable for the retrieval of aerosol height for cloud free scenes over the oceans (Dubuisson et al., 2009; Boesche et al., 2009). Therefore, it is interesting to know if there is any aerosol information in the FRESCO cloud product, and how to interpret it. The FRESCO retrievals are 
performed for all scenes globally. For scenes with absorbing aerosols the information could be aerosol information, or if there are clouds, a mixture of aerosol and cloud information.

The Absorbing Aerosol Index (AAI), derived from UV reflectances, is an operational product of SCIAMACHY, GOME-2 and OMI (Ozone Monitoring Instrument) (De Graaf et al., 2005; Tilstra et al., 2010; Herman et al., 1997; Torres et al., 1998, 2007). The aerosol types that are mostly seen in the AAI data are desert dust, biomass burning smoke and volcanic ash aerosols. The AAI is hardly sensitive to clouds; therefore it is derived for both cloud free and cloudy scenes (Torres et al., 1998, 2012; De Graaf et al., 2005; Penning de Vries and Wagner, 2011). It is not straightforward to use the AAI quantitatively, because the AAI is sensitive to aerosol particle size, aerosol layer height, aerosol optical thickness, and single scattering albedo (Torres et al., 1998; De Graaf et al., 2005). Both aerosol optical thickness and single scattering albedo can be simultaneously derived using observations of the AAI and reflectance at a near UV wavelength channel if the aerosol layer height is known (Torres et al., 1998). The AAI has been extensively used in the studies of biomass burning aerosols, desert dust and volcanic ash plumes (e.g. Kaufman et al., 2005; Fromm et al., 2006; Eckardt and Kuring, 2005; Dirksen et al., 2009; De Graaf et al., 2010a; Guan et al., 2010; Witte et al., 2011). The GOME2 AAI product is also used to support the Volcanic Ash Advisory Centres (VAAC, http://www.temis.nl/o3msaf/vaac/).

In this study we focus on the interpretation of the FRESCO cloud product for strongly absorbing aerosol events, especially desert dust, biomass burning smoke, and volcanic ash plumes. In order to identify aerosol events we use the AAI as an indicator. We first analyse FRESCO cloud data using simulated spectra with absorbing aerosols and then analyse FRESCO data from GOME-2 measurements for the selected events. The structure of the paper is as follows. The GOME2 FRESCO and AAI data and the method used in the analysis are described in Sect. 2. In Sect. 3 we simulate the effect of absorbing aerosols on the retrieved cloud pressure, effective cloud fraction, scene pressure, and scene albedo. Section 4 presents the analysis of GOME-2 retrieval results for scenes containing volcanic ash plumes, Saharan desert dust, biomass burning smoke in West Africa, and Russian wild fires. In Sect. 5 conclusions are given.

\section{Data sets and methodology}

\subsection{FRESCO cloud data}

GOME-2 is onboard the Metop-A satellite of EUMETSAT. Metop-A is a Sun-synchronised polar orbiting satellite with an overpass time of 09:30 local time (LT) at the equator. The swath width of the GOME-2 instrument is $1920 \mathrm{~km}$ with a pixel size of $40 \times 80 \mathrm{~km}^{2}$. The GOME-2 spectrum covers the wavelength range $240-790 \mathrm{~nm}$ (Munro et al., 2006). The
GOME-2 level 1 cloud product is based on the FRESCO algorithm (Wang and Stammes, 2007). In this analysis we use an improved FRESCO algorithm, FRESCO version 6 (v6).

In order to simulate the reflectance spectrum of a partly cloudy pixel inside and outside the $\mathrm{O}_{2}$ A band, a simple atmospheric model is used, in which the atmosphere above the ground surface (for the cloud free part of the pixel) or cloud (for the cloudy part of the pixel) is treated as an absorbing (due to oxygen) and purely Rayleigh scattering medium. Reflection occurs only at the surface and the cloud top. Surface and cloud are assumed to be Lambertian reflectors. The reflectance $R_{\text {sim }}\left(\lambda, \theta, \theta_{0}, \phi-\phi_{0}\right)$ at wavelength $\lambda$, viewing zenith angle $\theta$, solar zenith angle (SZA) $\theta_{0}$, and relative azimuth angle $\phi-\phi_{0}$ is then given by Eq. (1),

$R_{\mathrm{sim}}=c T_{\mathrm{c}}\left(z_{\mathrm{c}}\right) A_{\mathrm{c}}+c R_{\mathrm{c}}\left(z_{\mathrm{c}}\right)+(1-c) T_{\mathrm{s}}\left(z_{\mathrm{s}}\right) A_{\mathrm{s}}+(1-c) R_{\mathrm{s}}\left(z_{\mathrm{s}}\right) .(1)$

If $c=1$, the surface related terms vanish and Eq. (1) is simplified to Eq. (2),

$R_{\mathrm{sim}}=T_{\mathrm{c}}\left(z_{\mathrm{sc}}\right) A_{\mathrm{sc}}+R_{\mathrm{c}}\left(z_{\mathrm{sc}}\right)$.

Note that the wavelength and angle dependences are omitted in Eqs. $(1,2)$ for $R_{\mathrm{sim}}, T_{\mathrm{c}}, R_{\mathrm{c}}, T_{\mathrm{s}}$, and $R_{\mathrm{s}}$. In the above equations, $c$ is the effective cloud fraction at the $\mathrm{O}_{2} \mathrm{~A}$ band, $A_{\mathrm{c}}$ is the cloud albedo, $A_{\mathrm{S}}$ is the surface albedo, and $A_{\mathrm{sc}}$ is the scene albedo. $T\left(\lambda, z_{\mathrm{s}}, \theta, \theta_{0}\right), T\left(\lambda, z_{\mathrm{c}}, \theta, \theta_{0}\right)$, and $T\left(\lambda, z_{\mathrm{sc}}\right.$, $\left.\theta, \theta_{0}\right)$ are the direct atmospheric transmittances for light entering the atmosphere from the solar direction, propagating down to different levels with surface height $z_{\mathrm{s}}$, cloud height $z_{\mathrm{c}}$, and scene height $z_{\mathrm{sc}}$, respectively, then propagating to the top of the atmosphere (TOA) in the direction of the satellite. The $\mathrm{O}_{2}$ absorption and single Rayleigh scattering are taken into account in the light paths for the transmittances and the single Rayleigh scattering reflectances above the cloud $\left(R_{\mathrm{c}}\right)$ and the surface $\left(R_{\mathrm{S}}\right)$, respectively (Wang et al., 2008). The transmittances and reflectances are pre-calculated and stored in look-up tables (LUT).

In FRESCO v6, effective cloud fraction, cloud pressure (or cloud height), scene albedo and scene pressure (or scene height) are derived for every pixel. Scene albedo and scene pressure were already retrieved in previous FRESCO versions but only for pixels flagged as having snow/ice on the surface. In the FRESCO algorithm, the cloud height, scene height and surface height are converted to cloud pressure, scene pressure and surface pressure using the mid-latitude summer atmospheric profile (Anderson et al., 1986). Therefore, in FRESCO products the terms "height" and "pressure" are interchangeable. The effective cloud fraction and cloud pressure (cloud height) are retrieved using Eq. (1), whereas the cloud albedo is assumed to be 0.8 (Koelemeijer et al., 2001), because cloud albedo and cloud fraction information cannot be separated from the $\mathrm{O}_{2} \mathrm{~A}$ band spectra due to the large pixel size of GOME- 2 and other similar satellite spectrometers. Because of the wavelength dependence of Rayleigh scattering, the effective cloud fraction derived from 
the $\mathrm{O}_{2} \mathrm{~A}$ band is larger than that in the UV. Surface albedo and surface height are taken from auxiliary databases.

Using Eq. (2), the scene albedo and scene pressure are derived by assuming the cloud fraction to be 1 (Koelemeijer et al., 2001; Stammes et al., 2008; Wang et al., 2008). Large aerosol plumes often cover several GOME-2 pixels. Thus, it seems reasonable to assume an aerosol or cloud fraction of 1 in these situations. The retrieved scene pressure and scene albedo are a radiance-weighted average of the cloudy and cloud free parts of the pixels, because the GOME-2 pixels are often partly cloudy (Krijger et al., 2005). If a pixel is fully covered with clouds having optical thickness larger than about 35 (Koelemeijer et al., 2001), the FRESCO scene pressure is the same as the cloud pressure.

The FRESCO v6 algorithm is an upgrade of the FRESCO+ (or FRESCO v5) algorithm using new databases and providing more output data (Wang and van der A, 2011; Wang et al., 2011). FRESCO v6 uses the high spatial resolution $\left(0.25^{\circ} \times 0.25^{\circ}\right)$ surface albedo climatology derived from MERIS (Popp et al., 2011) and the latest $\mathrm{O}_{2}$ line parameters from the HITRAN 2008 database (Rothman et al., 2009). Therefore, the effective cloud fraction and cloud pressure are retrieved more accurately. Because the absorption in the $\mathrm{O}_{2} \mathrm{~A}$ band is slightly stronger in HITRAN 2008 than in HITRAN 2004, the FRESCO v6 global mean cloud pressure is about $10 \mathrm{hPa}$ lower than for FRESCO v5. The HITRAN database change has no effect on the FRESCO effective cloud fraction. The difference between the effective cloud fraction in FRESCO v6 and v5 is entirely due to the MERIS surface albedo (Popp et al., 2011). The MERIS surface albedo is only available over land; over ocean the GOME surface albedo $\left(1^{\circ} \times 1^{\circ}\right)$ is used (Koelemeijer et al., 2003). Thus, in FRESCO v6 the effective cloud fraction is expected to be improved with respect to v 5 mainly over land and at coastal regions.

\subsection{Absorbing Aerosol Index data}

The operational GOME-2 Absorbing Aerosol Index (AAI), produced by the O3M SAF (Ozone and Atmospheric Chemistry Satellite Application Facility) of EUMETSAT, is derived from the 340/380 nm wavelength pair (Tilstra et al., 2010; De Graaf et al., 2010b). The part of the reflectance spectrum that contains this wavelength pair is measured simultaneously with the $\mathrm{O}_{2}$ A band spectrum from which the FRESCO cloud products are derived. As a result, the GOME2 AAI and FRESCO data are collocated. The main advantage of the AAI over other aerosol detection techniques is its ability to detect absorbing aerosols over both land and sea surfaces, even in the presence of clouds. The latter property makes it very suited for the analysis performed in this paper.

The AAI has been shown to be sensitive to aerosol single scattering albedo, aerosol optical thickness (AOT), aerosol layer height, scattering geometry, and surface height (Torres et al., 1998; De Graaf et al., 2005). From this list of parame- ters, the aerosol layer height and the aerosol optical thickness are the most dominant. Generally speaking, aerosol plumes with large optical thickness and/or located at higher altitudes produce larger AAI values than plumes that are optically thin or are close to the surface (De Graaf et al., 2005; Torres et al., 1998; Jeong and Hsu, 2008).

\subsection{MODIS data}

The Moderate Resolution Imaging Spectroradiometer (MODIS) onboard the NASA EOS Terra satellite has an equator overpass time of 10:30 LT, which is about $1 \mathrm{~h}$ later than GOME-2 (09:30LT). Because of the difference between the GOME-2 and MODIS overpass times, we cannot validate the GOME-2 cloud product by using MODIS data. The MODIS RGB images and fire counts maps are used to visually determine the cloud amount and the location of the aerosol plume.

\subsection{Methodology}

The interpretation of the FRESCO product for absorbing aerosol events is based on the relationship between the AAI and the FRESCO products. If the AAI values are correlated with the effective cloud fractions and/or scene albedos, then these two FRESCO products may contain aerosol optical thickness information. If the AAI values are correlated with FRESCO cloud pressures and/or scene pressures, then these FRESCO products may contain information on aerosol height. The FRESCO products may be interpreted differently for cloud free scenes and cloudy scenes. In order to understand the FRESCO product for absorbing aerosol events, we first investigate the FRESCO product using simulated $\mathrm{O}_{2} \mathrm{~A}$ band spectra for scenes containing absorbing aerosols and clouds. Next, strong absorbing aerosol events are selected from GOME-2 AAI global maps for 2010 and 2011 with AAI values larger than 1 . In order to get more significant statistics, we choose aerosol plumes with an extent of several degrees in latitude and longitude. In the analysis we select four typical events with absorbing aerosols: a volcanic ash plume event, a desert dust event, a biomass burning smoke event, and a wild fire smoke event. For all the selected aerosol events we also verify the plumes using the corresponding MODIS/Terra images. For every event we study the relationship between GOME-2 AAI and GOME-2 FRESCO effective cloud fraction, cloud pressure, scene albedo and scene pressure, respectively. 
Table 1. Aerosol and cloud microphysics models used in the Mie calculations. $r_{\text {eff }}$ : effective radius of cloud droplet size distribution, $v_{\text {eff }}$ : effective variance of cloud droplet size distribution.

\begin{tabular}{|c|c|c|c|c|}
\hline & $\begin{array}{l}\text { Biomass burning aerosols } \\
\text { BBA (Case } 1 \text { ) }\end{array}$ & BBA (Case 2) & Dust aerosols & Clouds \\
\hline Size distribution & bi-modal log-normal & bi-modal log-normal & bi-modal log-normal & two-parameter Gamma \\
\hline Geometric radius fine mode $(\mu \mathrm{m})$ & 0.117 & 0.117 & 0.052 & $r_{\text {eff }}=6 \mu \mathrm{m}$ \\
\hline Geometric radius coarse mode $(\mu \mathrm{m})$ & 0.255 & 0.255 & 0.670 & \\
\hline Standard deviation fine mode $(\mu \mathrm{m})$ & 1.25 & 1.25 & 1.697 & $v_{\text {eff }}=0.15 \mu \mathrm{m}$ \\
\hline Standard deviation coarse mode $(\mu \mathrm{m})$ & 1.40 & 1.40 & 1.806 & \\
\hline Number fraction of coarse mode & 0.0003 & 0.0003 & 0.00435 & \\
\hline Refractive index at $340 \mathrm{~nm}$ & $1.54+0.060 i$ & $1.51+0.03 i$ & $1.55+0.006 i$ & $1.36+0 i$ \\
\hline Refractive index at $380 \mathrm{~nm}$ & $1.54+0.048 i$ & $1.51+0.02 i$ & $1.55+0.0042 i$ & $1.35+0 i$ \\
\hline Refractive index at $550 \mathrm{~nm}$ & $1.54+0.018 i$ & $1.51+0.01 i$ & $1.55+0.004 i$ & $1.34+0 i$ \\
\hline Refractive index at $760 \mathrm{~nm}$ & $1.54+0.018 i$ & $1.51+0.01 i$ & $1.55+0.004 i$ & $1.33+0 i$ \\
\hline
\end{tabular}

Table 2. Aerosol and cloud optical properties from the Mie calculations. SSA: single scattering albedo, ASY: asymmetry parameter, EXT: extinction efficiency.

\begin{tabular}{llll|lll|lll|ll|ll}
\hline & \multicolumn{3}{c|}{ BBA Case 1 } & \multicolumn{3}{c}{ BBA Case 2 } & \multicolumn{3}{c}{ Dust } & \multicolumn{3}{c}{ Clouds } \\
\hline Wavelength (nm) & SSA & ASY & EXT & SSA & ASY & EXT & SSA & ASY & EXT & SSA & ASY & EXT \\
340 & 0.789 & 0.711 & 2.657 & 0.877 & 0.704 & 2.500 & 0.871 & 0.722 & 1.945 & 1 & 0.853 & 2.092 \\
380 & 0.821 & 0.679 & 2.313 & 0.911 & 0.673 & 2.117 & 0.900 & 0.712 & 1.815 & 1 & 0.854 & 2.101 \\
550 & 0.903 & 0.551 & 1.087 & 0.939 & 0.549 & 0.949 & 0.907 & 0.694 & 1.469 & 1 & 0.851 & 2.131 \\
760 & 0.862 & 0.367 & 0.451 & 0.910 & 0.361 & 0.384 & 0.917 & 0.679 & 1.313 & 1 & 0.845 & 2.165 \\
\hline
\end{tabular}

\section{FRESCO retrievals using simulated spectra of scenes containing clouds and aerosols}

\subsection{Simulations of $\mathrm{UV}$ reflectance and $\mathrm{O}_{2} \mathrm{~A}$ band spectra}

The simulations were performed for two kinds of biomass burning aerosols (BBA) and dust aerosols in cloud free and fully cloudy scenes. The scattering properties of the aerosols and clouds were approximated using Mie calculations (De Rooij and Van der Stap, 1984). The characteristics of the aerosol and cloud models and the optical properties calculated from Mie theory are presented in Tables 1 and 2.

The first biomass burning aerosol model was taken from De Graaf et al. (2012) (called Case 1), which represents aged smoke. The absorption Ångström exponent was 2.91 in the $\mathrm{UV}$, which is in good agreement with the values reported by Jethva and Torres (2011). This aerosol model represents a strongly absorbing aerosol case, having a single scattering albedo of 0.82 at $380 \mathrm{~nm}$. The second biomass burning aerosol model (Case 2) has a single scattering albedo of 0.91 at $380 \mathrm{~nm}$, which is close to the single scattering albedo of African savanna biomass burning aerosols (Dubovik et al., 2002).

For dust aerosols, we used the particle size distribution parameters from the dust aerosol model of the OMI near-UV algorithm (Torres et al., 2007). The complex refractive index for the dust aerosols was taken from Sinyuk et al. (2003).
Both aerosol models use a bi-modal log-normal size distribution (Boesche et al., 2006).

The wavelength dependence of the AOT was taken into account using the extinction efficiency, which is the ratio between extinction cross-section and geometric cross-section (Hansen and Travis, 1974). For example, if the extinction efficiency of the biomass burning aerosol is 0.45 at $760 \mathrm{~nm}$ and 1.09 at $550 \mathrm{~nm}$, then an AOT of 1 at $760 \mathrm{~nm}$ corresponds to an AOT of $1.09 / 0.45=2.42$ at $550 \mathrm{~nm}$. The biomass burning aerosols used in this paper are more absorbing than the dust aerosols.

The $\mathrm{O}_{2}$ A band spectra and the reflectances at 340 and $380 \mathrm{~nm}$ were simulated using the Doubling Adding KNMI (DAK) code (De Haan et al., 1987; Stammes, 2001). Polarisation was included in the $340 / 380 \mathrm{~nm}$ reflectance calculations but not in the $\mathrm{O}_{2} \mathrm{~A}$ band calculations. Compared to the $\mathrm{UV}$, the effect of neglecting polarisation on the radiance in the $\mathrm{O}_{2} \mathrm{~A}$ band is very small because Rayleigh scattering is very small there. In addition, including polarisation in the $\mathrm{O}_{2}$ A band would be computationally too expensive.

The mid-latitude summer atmospheric profile was used in the simulations (Anderson et al., 1986). We set a biomass burning aerosol layer between 4 and $5 \mathrm{~km}$ to represent smoke events using BBA Cases 1 and 2. A low altitude aerosol layer between 1 and $2 \mathrm{~km}$ was simulated using BBA Case 2 without clouds. The dust aerosol layers between 2 and $3 \mathrm{~km}$ and between 5 and $6 \mathrm{~km}$ are simulated to represent typical desert dust aerosol heights (Yu et al., 2010). In a volcanic 

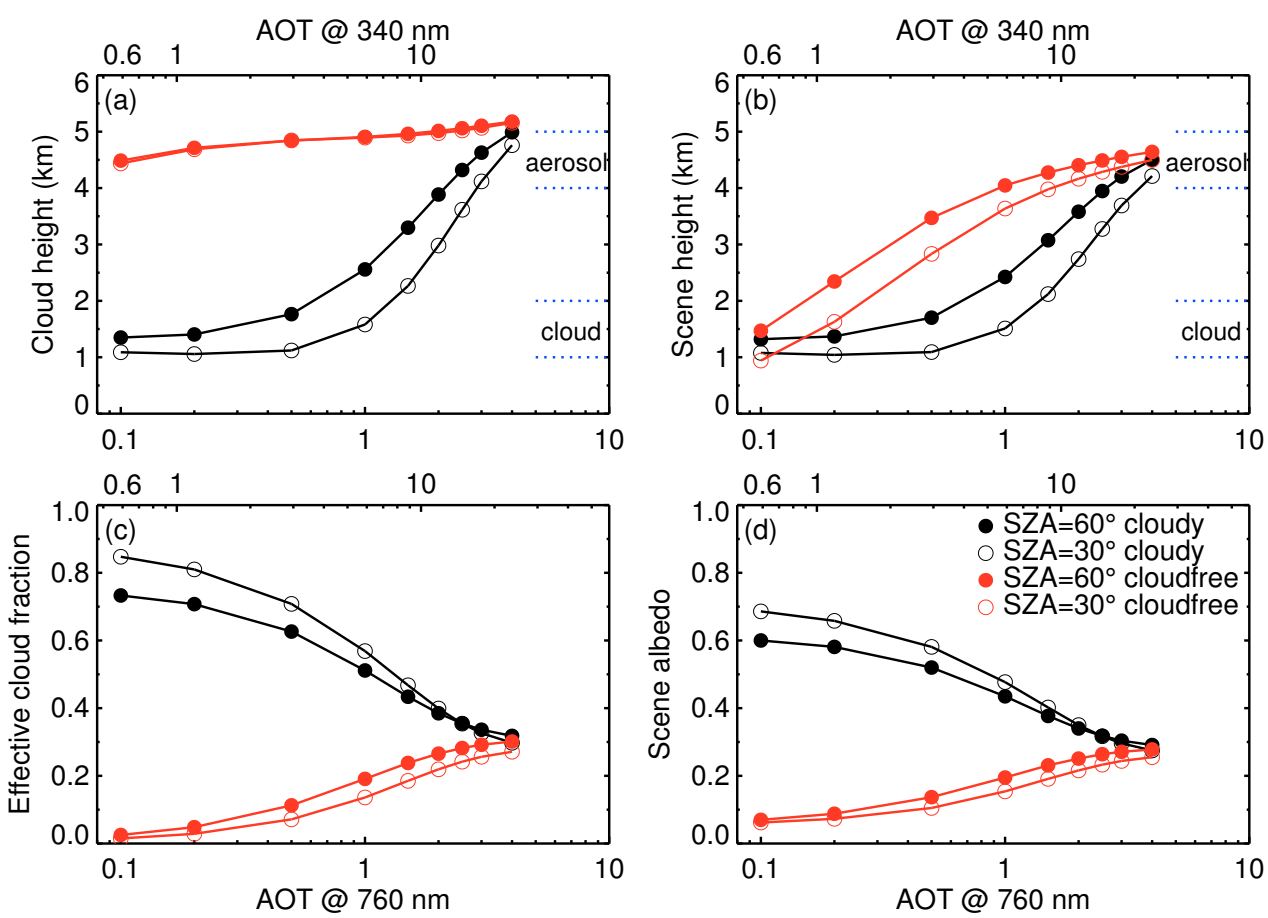

Fig. 1. FRESCO retrieval results of (a) cloud height, (b) scene height, (c) effective cloud fraction, and (d) scene albedo using simulated $\mathrm{O}_{2}$ A band spectra for biomass burning aerosol Case 1 in a cloud free scene and in a cloudy scene (COT=20). Aerosol optical thickness (AOT) is $0-4$. The cloud layer is located between 1 and $2 \mathrm{~km}$ altitude and the location of the aerosol layer is between 4 and $5 \mathrm{~km}$. The location of aerosol and cloud layers is indicated with dashed lines. Surface albedo is 0.05 . Results for two solar zenith angles are plotted, $60^{\circ}$ and $30^{\circ}$. Viewing direction is nadir. The y-axes, "cloud height" and "effective cloud fraction", represent "aerosol height" and "effective aerosol fraction" for cloud free scenes.

ash aerosol event, the aerosol layer could be at $10 \mathrm{~km}$, therefore we also simulated a dust aerosol layer between 9 and $10 \mathrm{~km}$. In this work dust particles were used as a proxy for volcanic ash particles.

For the cloudy scenes, a cloud layer was set below the aerosol layer, between 1 and $2 \mathrm{~km}$, with a cloud optical thickness (COT) of 20. We set the aerosol layer above the cloud layer, because if the aerosol layer is below the clouds, it may not be observed from satellite, particularly for optically thick cloud cases (De Graaf et al., 2005). The AOT range was 0-4 at $760 \mathrm{~nm}$. In the calculation of reflectances at $340 / 380 \mathrm{~nm}$, AOTs at $340 / 380 \mathrm{~nm}$ were derived from the AOT at $760 \mathrm{~nm}$ using the extinction efficiency values. The surface albedo was assumed to be 0.05 in all UV and $\mathrm{O}_{2} \mathrm{~A}$ band simulations, which is close to the surface albedo of the oceans (Koelemeijer et al., 2003; Jin et al., 2004). The solar zenith angle (SZA) range was $0-85^{\circ}$ and the viewing direction in the simulations was nadir. Pseudo-spherical correction was used in DAK for the simulations at large SZAs. The scenes were assumed to be fully covered with aerosols or aerosols and clouds. The FRESCO cloud algorithm (v6) was applied to the simulated spectra to retrieve effective cloud fraction, cloud height, scene albedo, and scene height. The AAI was calculated from the reflectances at $340 / 380 \mathrm{~nm}$ (De Graaf et al., 2005).

\subsection{Simulations for biomass burning aerosols}

The FRESCO retrievals for the biomass burning aerosols cases are shown in Figs. 1-3 as a function of AOT. The yaxes of the figures are called cloud height or effective cloud fraction although in cloud free scenes they represent aerosol height or effective aerosol fraction. For the cloud free scenes, one would expect FRESCO to be able to retrieve aerosol height and effective aerosol fraction. Indeed, as shown in Figs. 1 and 2, the retrieved aerosol heights are close to the top of the aerosol layer at about $5 \mathrm{~km}$ if AOT is larger than 0.2 (at $760 \mathrm{~nm}$ ). The retrieved aerosol height slightly depends on the AOT. The single scattering albedo of BBA Case 1 aerosol is smaller than that of BBA Case 2 aerosol, therefore FRESCO retrieved aerosol heights are higher for Case1 than Case 2. If the BBA Case 2 aerosol is at $1-2 \mathrm{~km}$, the FRESCO retrieved aerosol height is between $1.25-1.75 \mathrm{~km}$, which is within the aerosol layer (see Fig. 3).

The retrieved scene height is lower than the aerosol layer bottom height when AOT $<1$ (at $760 \mathrm{~nm}$ ) in the cloud free scenes, because of the contribution of surface reflection. For optically thicker aerosol scenes, most photons are absorbed 

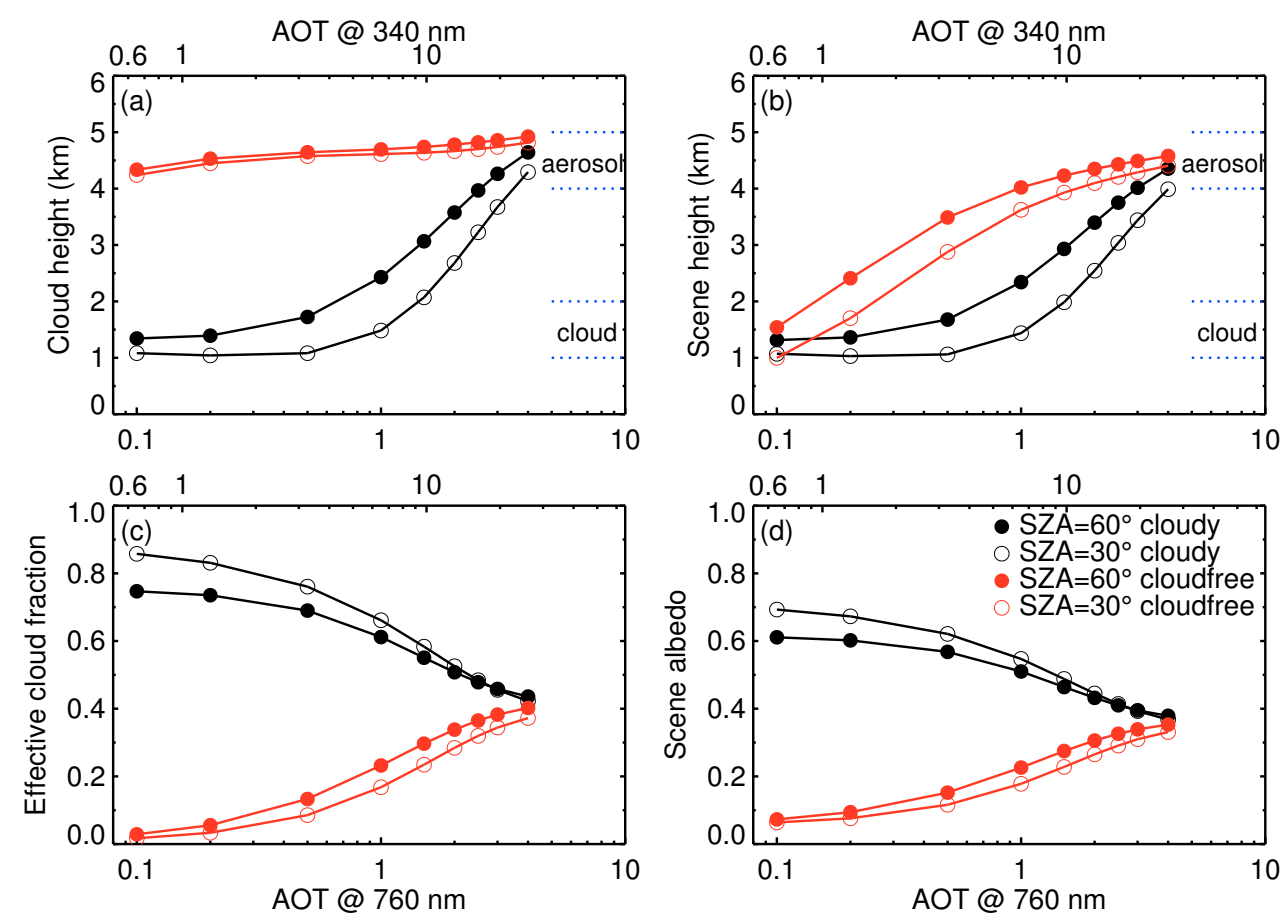

Fig. 2. Same as Fig. 1 but for biomass burning aerosol Case 2.
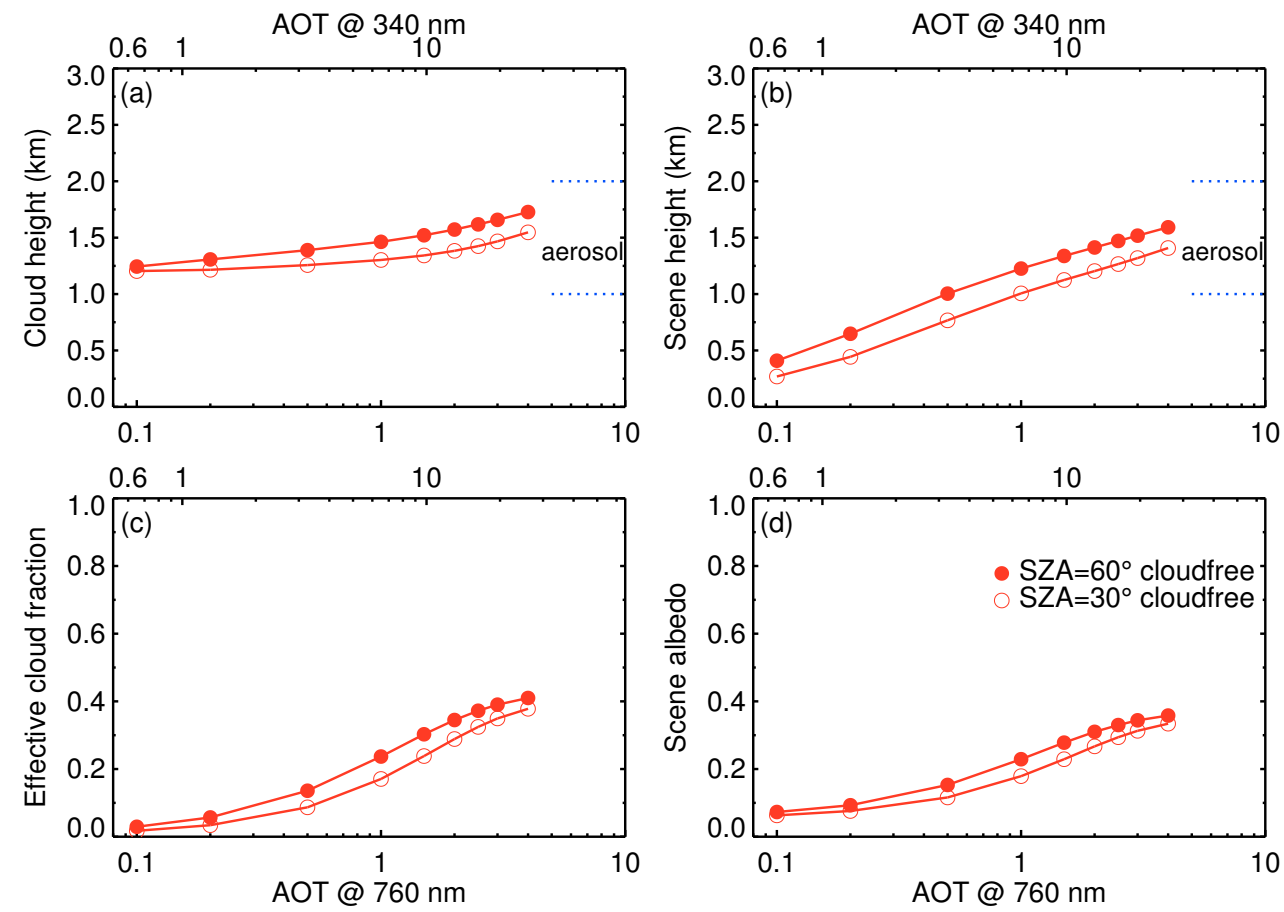

Fig. 3. Same as Fig. 2 but for the location of the BBA Case 2 aerosol layer between 1 and $2 \mathrm{~km}$ and only cloud free scenes. 

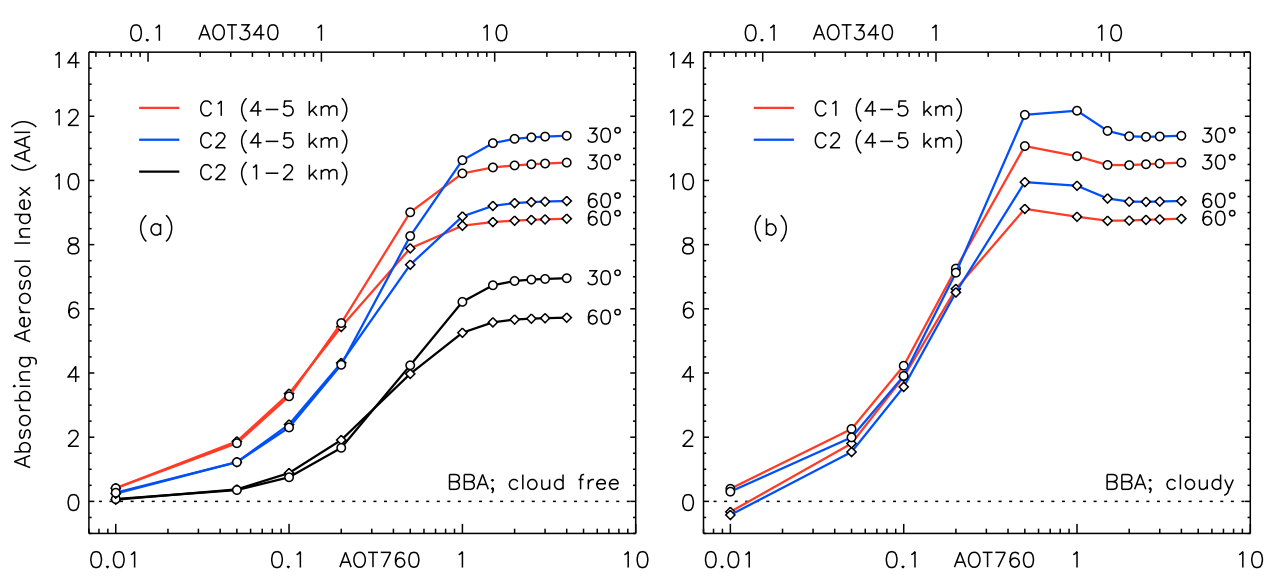

Fig. 4. Simulations of the absorbing aerosol index for biomass burning aerosols as a function of aerosol optical thickness in (a) cloud free scene and (b) cloudy scene. The scenes are the same as in Figs. 1-3. Results for two solar zenith angles are plotted, $60^{\circ}$ and $30^{\circ}$. Viewing direction is nadir. The $\mathrm{x}$-axis AOT340 is for BBA Case 2 (C2), which is very similar to AOT340 for BBA Case 1 (C1).

by the aerosol layer and the light path is not affected by the surface reflection, therefore the retrieved scene height corresponds closely to the height of the aerosol layer. The scene height increases with solar zenith angle, which can also be explained by the longer slant light paths at larger SZA. This behaviour is similar to that found in simulations for a singlelayer cloud (Wang et al., 2008).

The effective cloud (aerosol) fraction and scene albedo are both increasing with AOT in cloud free scenes. As shown in Figs. 1 and 2, the scenes with BBA Case 1 aerosols have smaller effective cloud (aerosol) fractions than the scenes with BBA Case 2 aerosols. This is because the BBA Case 1 aerosol is more absorbing than the BBA Case 2 aerosol.

For the aerosols in cloudy scenes, the effective cloud fraction and scene albedo are larger than in the corresponding cloud free scenes, because the cloud layer reflects more light back to the top of the atmosphere. With increasing AOT, the effective cloud fraction and scene albedo decrease and converge, respectively, to the values of the cloud free scenes at AOT around 4 (at $760 \mathrm{~nm}$ ). This suggests that at large AOT, the surface and cloud layer do not contribute to the TOA reflectance in the $\mathrm{O}_{2}$ A band. As shown in Figs. 1a and 2a the retrieved cloud height is close to the cloud layer height when $\mathrm{AOT}<1$ and close to the aerosol layer height when AOT $>2.5$ (at $760 \mathrm{~nm}$ ).

The scene height shows a similar behaviour as the cloud height in the cloudy scene. The retrieved cloud height and scene height are both higher at large SZA than at small SZA. For the biomass burning aerosols used in this analysis, an AOT of 2.5 at $760 \mathrm{~nm}$ corresponds to an AOT of 6 at $550 \mathrm{~nm}$, which is quite large. Therefore, FRESCO can only retrieve aerosol height above clouds for extremely optically thick absorbing aerosol cases. For cloud free scenes, FRESCO can retrieve aerosol height when AOT $>0.1$ at $760 \mathrm{~nm}$.
Figure 4 shows the AAI values of the biomass burning aerosol cases of Figs. 1-3 for the cloud free and cloudy scenes. The AAI values increase with increasing AOT and saturate at AOT around 1 at $760 \mathrm{~nm}$ (AOT of 6 at $340 \mathrm{~nm}$ ). The AAI values also depend on solar zenith angle. For the aerosol optical properties of BBA Case 2, the scenes having an aerosol layer at $1-2 \mathrm{~km}$ have smaller AAI values than the scenes with an aerosol layer at $4-5 \mathrm{~km}$. From the simulated FRESCO retrievals shown in Fig. 3, it appears that FRESCO can retrieve aerosol height for the cloud free cases if AAI $>1$. For cloudy scenes with BBA Case 2 aerosol, FRESCO can retrieve aerosol height if AAI $>8$ (at a SZA of $60^{\circ}$ ). In this paper we use the AAI to select absorbing aerosol scenes. The wavelength dependence of the AOT and the height of the aerosol layer can lead to different relationships between AAI and FRESCO retrievals, even if the other aerosol optical properties are the same. Therefore, we do not attempt to determine the quantitative relationship between the AAI and FRESCO retrievals.

\subsection{Simulations for dust aerosols}

The FRESCO retrievals for the dust/ash aerosol layer at 9$10 \mathrm{~km}, 5-6 \mathrm{~km}$ and $2-3 \mathrm{~km}$ are illustrated in Figs. 5-7, respectively. FRESCO can retrieve aerosol height for these dust aerosols in cloud free scenes. However, the retrieved aerosol height varies from the bottom to the top of the aerosol layer, depending on the AOT, SZA and actual aerosol layer height. At large AOT, the retrieved aerosol height can be above the aerosol layer top height. This is because the light path in the scene with the absorbing aerosols is shorter than the light path in a scene with a purely scattering cloud layer having the same optical thickness. In order to approximate the light path using a Lambertian reflector, the FRESCO algorithm has to put the Lambertian reflector at a higher altitude. This effect 

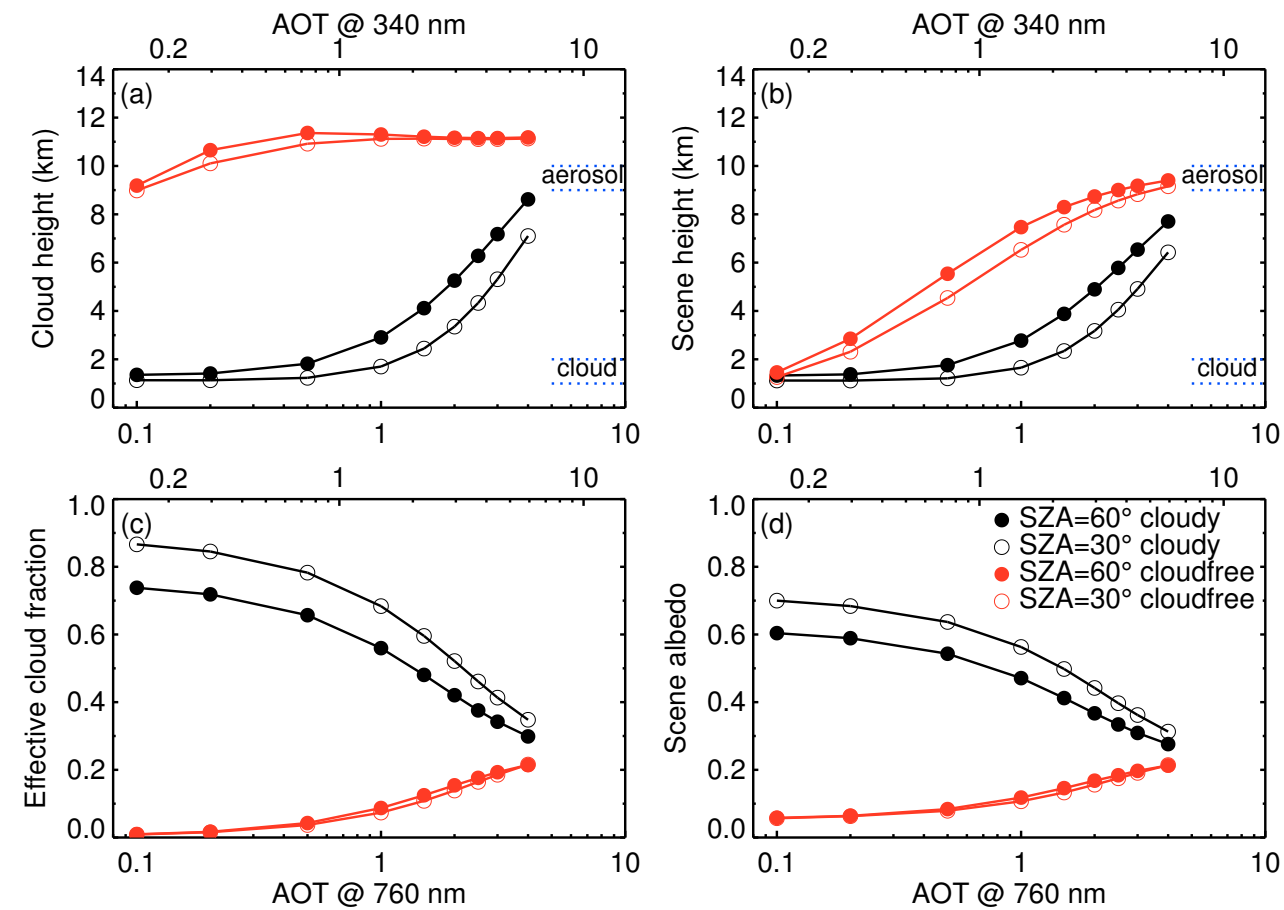

Fig. 5. FRESCO retrieval results of (a) cloud height, (b) scene height, (c) effective cloud fraction, and (d) scene albedo using simulated $\mathrm{O}_{2} \mathrm{~A}$ band spectra for dust aerosols in a cloud free scene and in a cloudy scene (COT=20). The aerosol optical thickness (AOT) is 0-4. The cloud layer is located between 1 and $2 \mathrm{~km}$ altitude, and the location of the aerosol layer is between 9 and $10 \mathrm{~km}$. The location of aerosol and cloud layers is indicated with dashed lines. Surface albedo is 0.05 . Results for two solar zenith angles are plotted, $60^{\circ}$ and $30^{\circ}$. Viewing direction is nadir. The y-axes, "cloud height" and "effective cloud fraction", represent "aerosol height" and "effective aerosol fraction" for cloud free scenes.
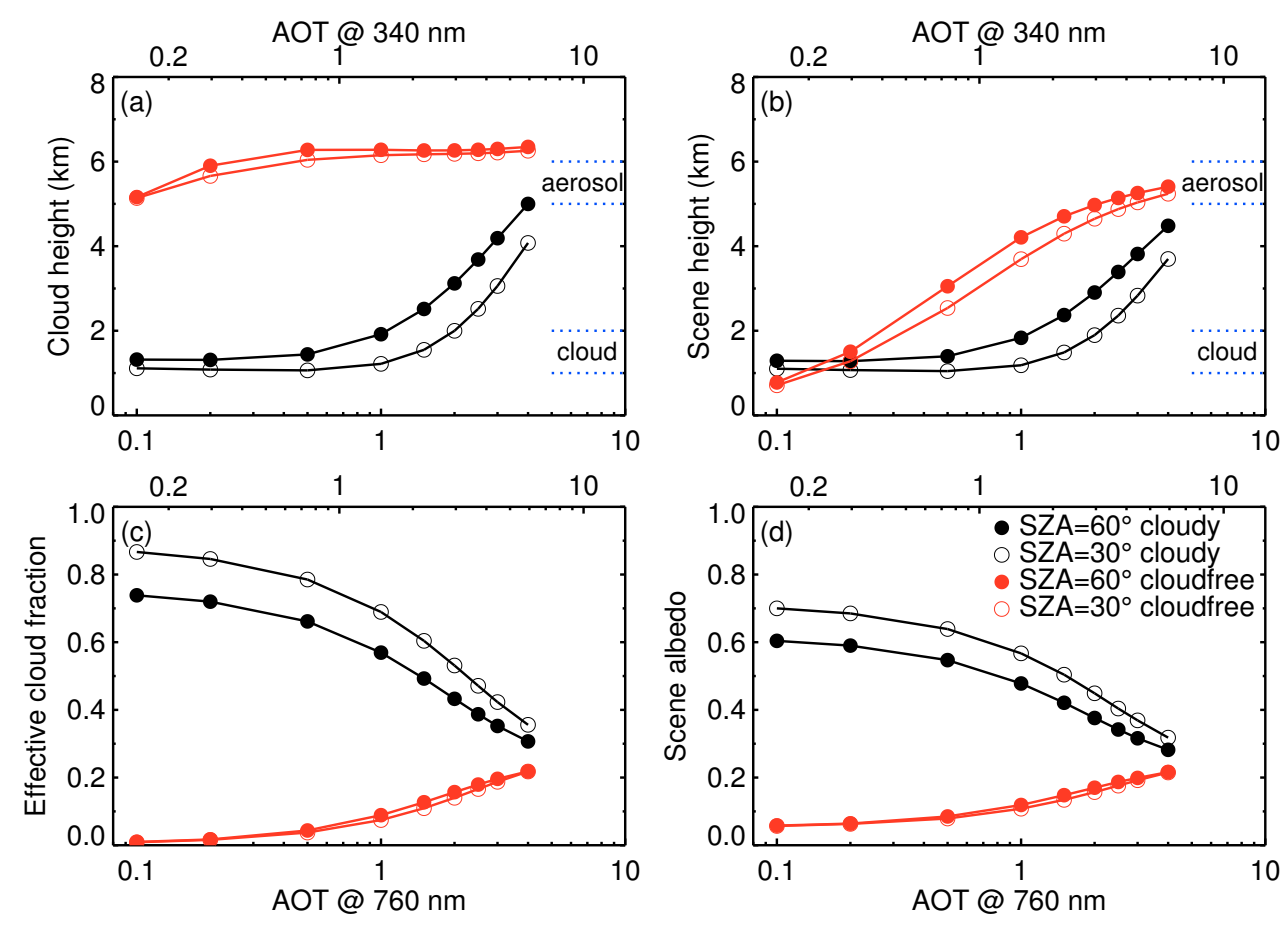

Fig. 6. Same as Fig. 5 but for the location of the dust aerosol layer between 5 and $6 \mathrm{~km}$. 

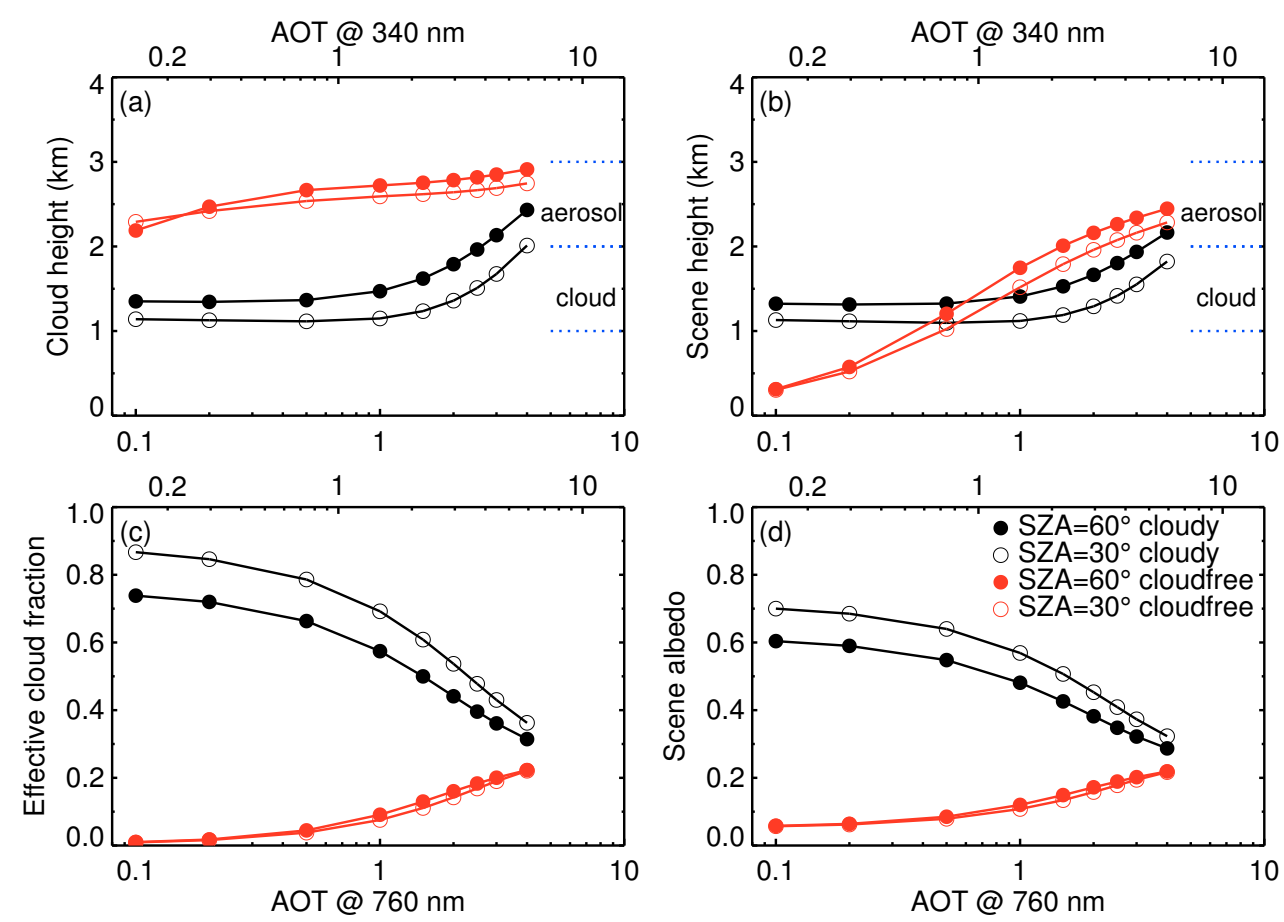

Fig. 7. Same as Fig. 5 but for the location of the dust aerosol layer between 2 and $3 \mathrm{~km}$.
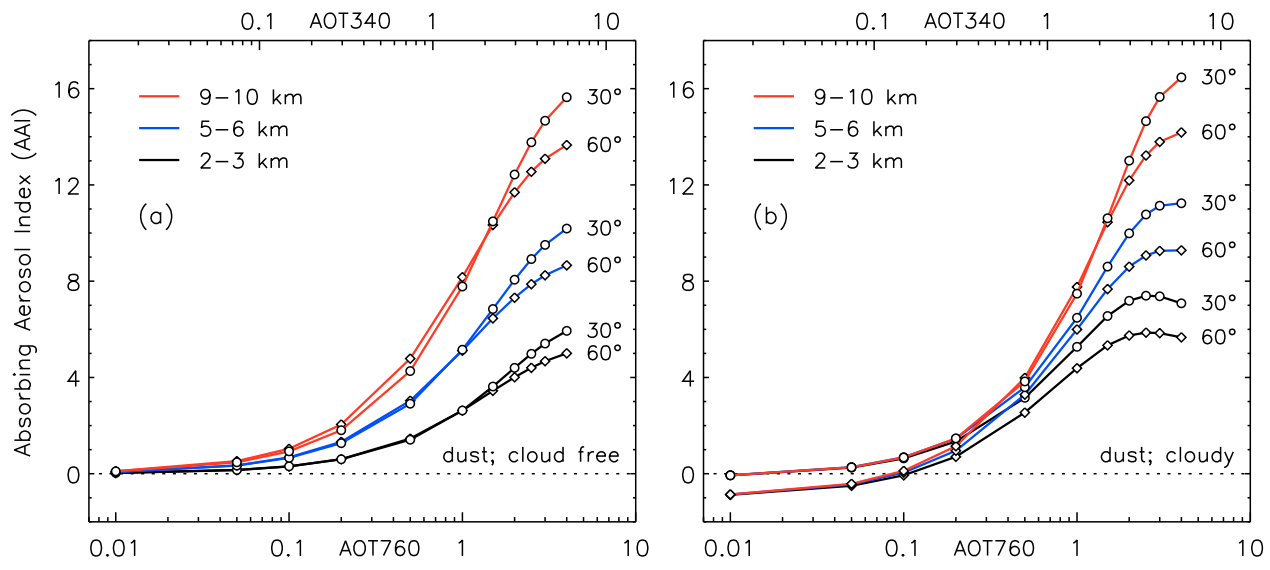

Fig. 8. Simulations of the absorbing aerosol index for dust aerosols as a function of aerosol optical thickness in (a) cloud free scene and (b) cloudy scene. The scenes are the same as in Figs. 5-7. Results for two solar zenith angles are plotted, $60^{\circ}$ and $30^{\circ}$. Viewing direction is nadir.

is larger for aerosol layers at higher altitude. The effective cloud (aerosol) fractions are very similar in Figs. 5-7 because the effective cloud (aerosol) fractions hardly depend on cloud (aerosol) height.

For the scene height and scene albedo retrieval, the retrieved scene height is the weighted average of the aerosol height and the surface height. Therefore, in the cloud free scene, the scene height is usually below the aerosol layer top height. For the dust aerosol cases, the scene height is close to the aerosol layer height (aerosol layer at 9-10 km) when
AOT $>3$ at $760 \mathrm{~nm}$ in the cloud free scenes and AOT $>4$ in the cloudy scenes. Because in the simulations at $760 \mathrm{~nm}$ the dust aerosols are less absorbing than the biomass burning aerosols, the absorption AOT is smaller in the dust aerosol scenes than in the biomass burning aerosol scenes. It is clearly difficult to retrieve the dust aerosol height for the cloudy scenes.

The corresponding AAI values for the dust aerosol cases are shown in Fig. 8. The AAI values in cloud free and cloudy scenes are very similar for the aerosol layer at $9-10 \mathrm{~km}$. If 

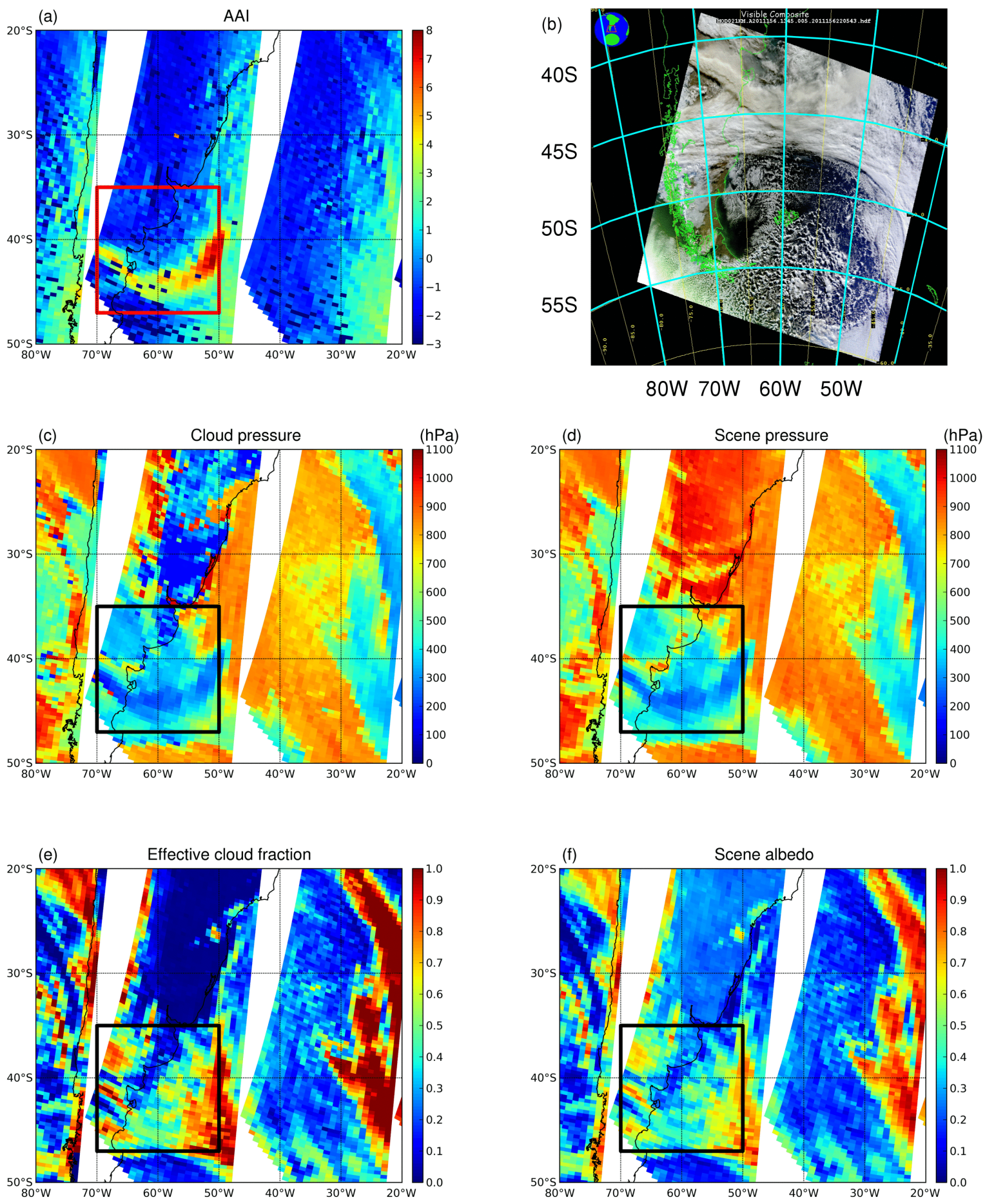

Fig. 9. (a) GOME-2 AAI image, (b) MODIS RGB image, (c) GOME-2 cloud pressure, (d) GOME-2 scene pressure, (e) GOME-2 effective cloud fraction, and (f) GOME-2 scene albedo for the Puyehue volcanic ash plume on 5 June 2011. The location of the plume is indicated with a box in the GOME-2 images. The plume in the box was measured around 12:50 UTC. MODIS image was measured at 13:45 UTC and was downloaded from LAADS Web (http://ladsweb.nascom.nasa.gov/browse_images/). 

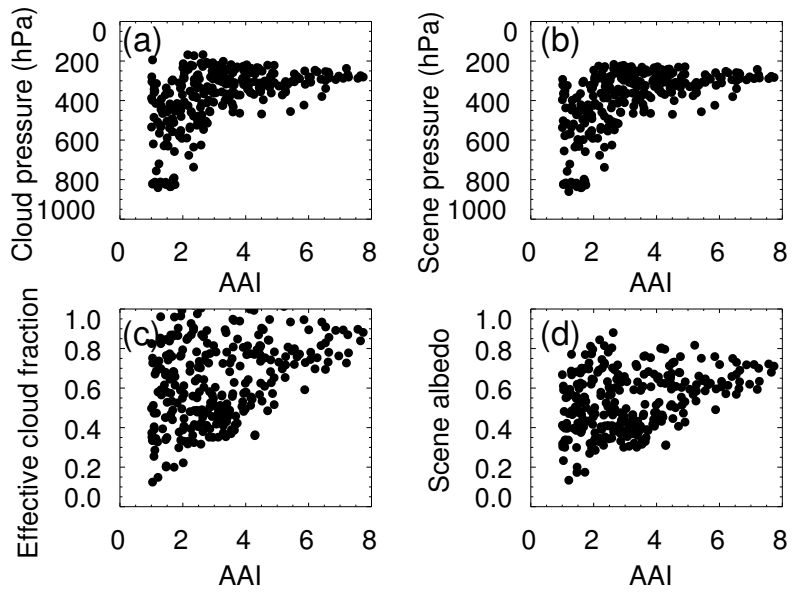

Fig. 10. Scatter plots of FRESCO (a) cloud pressure, (b) scene pressure, (c) effective cloud fraction, and (d) scene albedo versus absorbing aerosol index (AAI) from GOME-2 measurements of the Puyehue volcanic ash plume on 5 June 2011 around 12:50 UTC. The pixels used in the scatter plots are marked with a box in Fig. 9 in the region of $[35,47]^{\circ} \mathrm{S}$ and $[50,70]^{\circ} \mathrm{W}$.

the aerosol layer is at lower altitudes, the AAI for cloudy scenes is larger than the AAI for cloud free scenes, except for AOT $<0.1$ at $760 \mathrm{~nm}$. The AAI values increase with increasing AOT and increasing aerosol layer height and become saturated at AOT of around 4 at $760 \mathrm{~nm}$. If the dust aerosol layer is at 5-6 km, FRESCO can retrieve the aerosol height in a cloud free scene for a layer having an AAI of 1 and AOT of 0.1 at $760 \mathrm{~nm}$.

\section{GOME-2 FRESCO results for absorbing aerosol events}

Based on the simulations of Sect. 3, we would expect that the FRESCO cloud algorithm is able to retrieve aerosol height for cloud free scenes, although the results will depend on the type of absorbing aerosols and on AOT. For cloudy scenes, the FRESCO retrievals would be a mixture of cloud and aerosol properties. For extremely absorbing aerosol cases, FRESCO could retrieve aerosol height for cloudy scenes. In the following analysis we will show some examples of strongly absorbing aerosol events for cloud free and cloudy scenes.

\subsection{Volcanic ash plumes}

GOME-2 captured the ash plume from the eruption of the Chilean volcano called Puyehue-Cordón Caulle (elevation $2236 \mathrm{~m}, 40.59^{\circ} \mathrm{S}, 72.12^{\circ} \mathrm{W}$ ) firstly on 5 June 2011 and continued observations for several days. Figure 9 shows the MODIS RGB image, GOME-2 AAI and GOME-2 cloud images of 5 June 2011. The volcanic ash was injected at a high altitude and then transported to the east. According to the MODIS RGB image, the ash plume is in a cloud free region over land and above the clouds over the ocean. The plume can be clearly identified in the AAI image. In the FRESCO cloud pressure and scene pressure images the plume is clearly visible as a high cloud. According to the FRESCO cloud pressure, the volcanic plume is at $200 \mathrm{hPa}$ $(12 \mathrm{~km})$, which is higher than the surrounding clouds. The maximum AAI value is about 8 . The plume cannot be distinguished from clouds in the FRESCO effective cloud fraction and scene albedo maps, because the aerosol plume produces similar reflectances as the clouds nearby.

Figure 10 shows the scatter plots of the retrieved cloud information versus AAI for the pixels in the region of [35, $47]^{\circ} \mathrm{S}$ and $[50,70]^{\circ} \mathrm{W}$, which is marked with a box in Fig. 9. Some cloud pressure values are comparable to the scene pressure values because the effective cloud fractions are close to 1. As shown in Fig. 10, the cloud pressure and scene pressure both decrease with increasing AAI, whereas the effective cloud fraction and scene albedo both increase with increasing AAI. In aerosol-free cases over the dark ocean the effective cloud fraction and scene albedo are determined by the cloud optical thickness and geometric cloud fraction. In this case, the effective cloud fraction and scene albedo are determined by both clouds and aerosols.

The variation in AAI values of the selected aerosol plume as shown in Fig. 10 mainly depends on the height of the plume and the aerosol optical thickness, since the aerosol type and single scattering albedo values are probably similar in the selected region of the plume. All the pixels in the plume are measured by GOME-2 within a few minutes; the variation in the solar zenith angle is small. The larger AAI values are corresponding to optically thick parts of the plume and a large plume height. For parts of the plume having AAI values less than 2, the AOT is small, so that light can penetrate the aerosol layer and the retrieved plume height is close to the clouds or the surface beneath. This behaviour agrees with the simulations (see Figs. 5 and 8).

On 6 June 2011, the Puyehue volcanic ash plumes show up in the GOME-2 AAI image in three orbits (see Fig. 11). In contrast to Fig. 9, the plumes also appear in the effective cloud fraction and scene albedo images; this is because the plumes are optically thicker than the surrounding clouds. The MODIS image shows the left plume (plume in the left orbit, over land and close to the volcano). The left plume first went to the northeast, then turned to the southeast, forming a curl. The effective cloud fraction for the left plume is about 1. Inside the curl the aerosols are thinner because the surface is visible in the MODIS image and the FRESCO effective cloud fraction is about 0.3. In the FRESCO cloud images the thin aerosol plumes show up as having small effective cloud fractions, small scene albedos, high cloud pressures and high scene pressures; while the thick aerosol plumes result in large effective cloud fractions, large scene albedos, low cloud pressures and low scene pressures. 

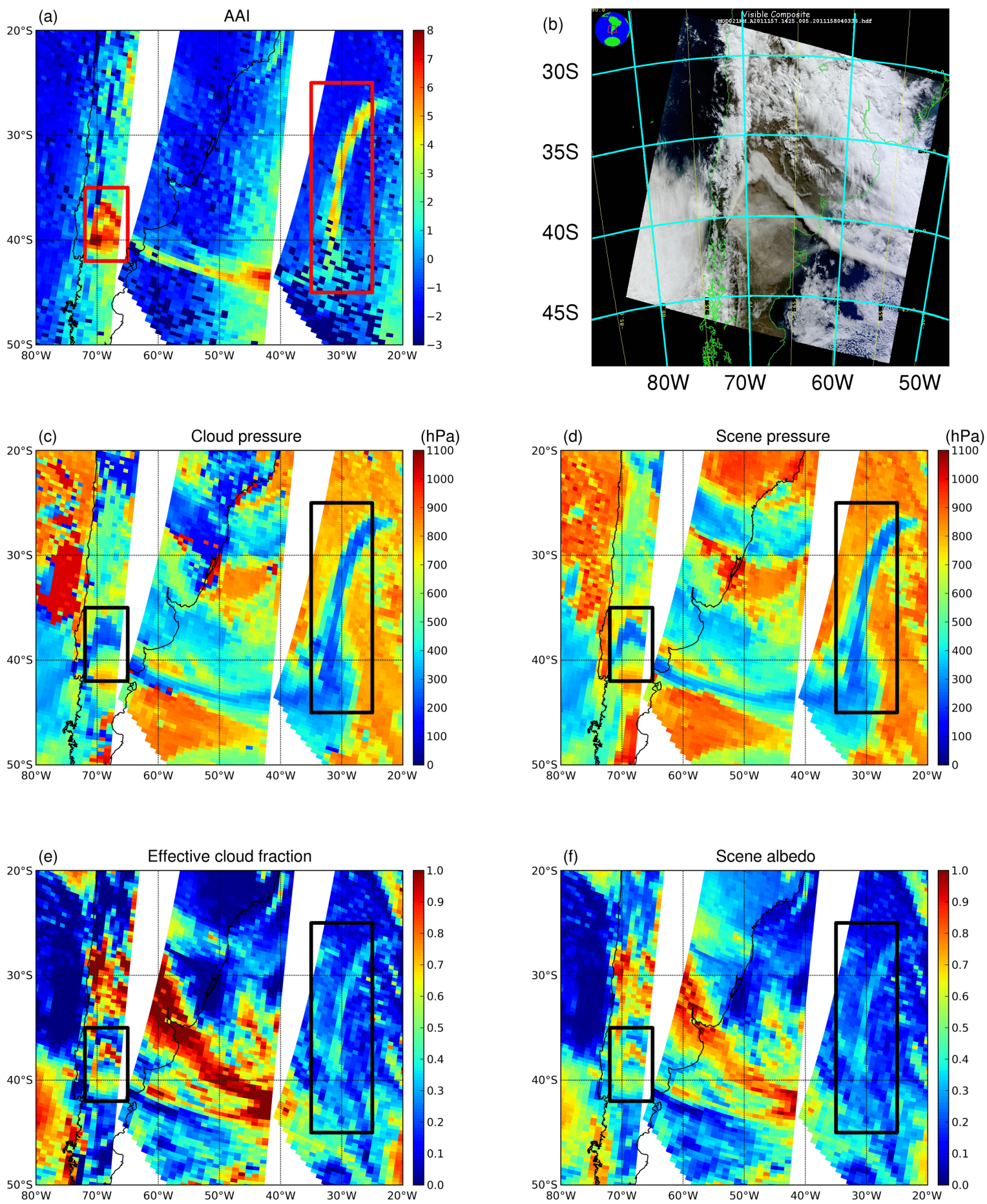

Fig. 11. (a) GOME-2 AAI image, (b) MODIS RGB image, (c) GOME-2 cloud pressure, (d) GOME-2 scene pressure, (e) GOME-2 effective cloud fraction, and (f) GOME-2 scene albedo for the Puyehue volcanic ash plume on 6 June 2011. The location of the plume is indicated with a box in the GOME-2 images. The plumes in the left and right boxes were measured around 14:10 and 10:45 UTC, respectively. The MODIS image was measured at 14:25 UTC. 

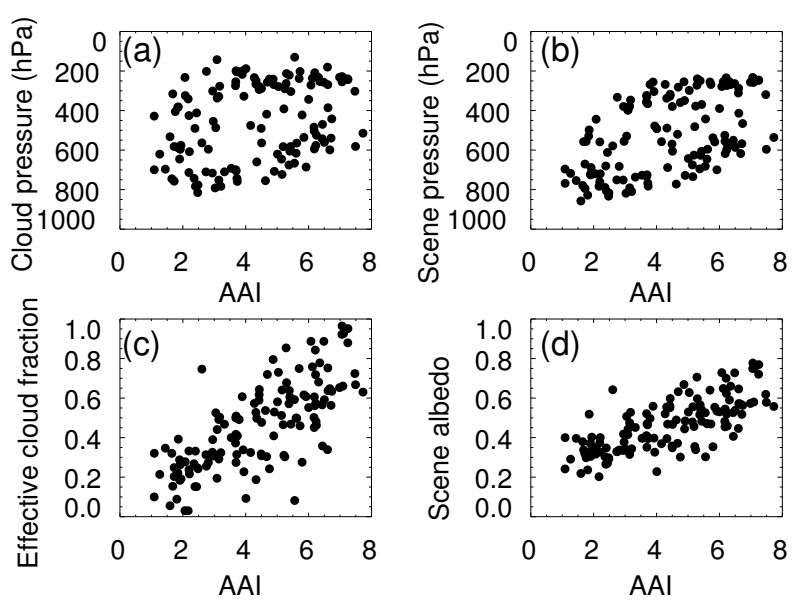

Fig. 12. Scatter plots of FRESCO (a) cloud pressure, (b) scene pressure, (c) effective cloud fraction, and (d) scene albedo versus absorbing aerosol index (AAI) from GOME-2 measurements of the Puyehue volcanic ash plume on 6 June 2011 around 14:10 UTC. The pixels used in the scatter plots are marked with the left box in Fig. 11 in the region of $[35,42]^{\circ} \mathrm{S}$ and $[65,72]^{\circ} \mathrm{W}$.

In the scatter plots for the left plume (see Fig. 12), the cloud pressures and scene pressures appear as two clusters, one at about $200 \mathrm{hPa}$ and the other at $600-800 \mathrm{hPa}$. The scene pressures are higher than the cloud pressures, which is in agreement with the simulations. The left plume is mainly in a cloud free region and the relation between the effective cloud fraction and the AAI is dominated by aerosols. The effective cloud fraction and scene albedo versus AAI plots have less scatter than in Fig. 10c and d, indicating less clouds. Figure 13 shows the scatter plots for the right side plume (along $30^{\circ} \mathrm{W}$ over the ocean). The plume is transported to the east at about $200 \mathrm{hPa}$, while the effective cloud fraction only ranges up to 0.4 , which points to optically thinner aerosols and clouds. The AAI values for this right plume go up to 6 , as compared to 8 for the left plume. The left plume has larger AAI values, which is probably due to larger aerosol optical thicknesses or more absorption. The right plume has been exposed to air longer than the plume close to the volcano; therefore it is more diluted by mixing with surrounding air or by deposition during the long range transport. The aerosol particles can also take up water vapour. Thus, the absorption of the aerosols is reduced, which also leads to smaller AAI values of the aerosol plume.

We have simulated the volcanic ash plume height on 6 June 2011 using the HYSPLIT model for volcanic ash (Draxler and Rolph, 2012; Rolph, 2012). It was reported that the Puyehue volcanic ash plume reached about $12 \mathrm{~km}$ on 4 June 2011 (http://www.volcanodiscovery.com/puyehue/ news.html). Therefore, we set the ash plume injection height at $12 \mathrm{~km}$ in the HYSPLIT volcanic ash model. The simulation was started on 4 June 2011 at 18:00 UTC, and continued for $48 \mathrm{~h}$. The simulated volcanic ash clouds on 6 June
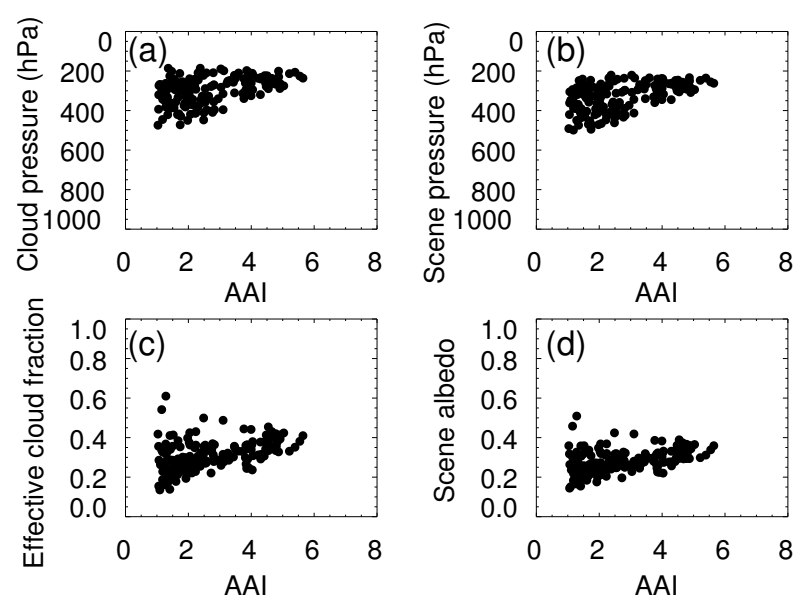

Fig. 13. Scatter plots of FRESCO (a) cloud pressure, (b) scene pressure, (c) effective cloud fraction, and (d) scene albedo versus absorbing aerosol index (AAI) from GOME-2 measurements of the Puyehue volcanic ash plume on 6 June 2011 around 10:45 UTC. The pixels used in the scatter plots are marked with the right box in Fig. 11 in the region of $[25,45]^{\circ} \mathrm{S}$ and $[25,35]^{\circ} \mathrm{W}$.

2011 at 12:00 UTC appeared to have similar patterns as those observed by GOME-2 on 6 June 2011 at 13:00 UTC (not shown). According to the HYSPLIT simulation, the plume in the right box of Fig. 11 was located between FL350 (flight level 35000 feet) and FL200, which has a good agreement with the GOME-2 FRESCO cloud pressure and scene pressure between 200-400 hPa.

In summary, the eruption of the Puyehue volcano in Chile in June 2011 produced a nice example for our FRESCO analysis. The volcanic ash plume is optically thick and its height is much higher than the clouds below it. If the plume would have been close to the surface or optically thin, the plume shape might not be so easily identified in the FRESCO cloud images. It shows that the FRESCO cloud pressure and scene pressure indicate the aerosol layer pressure for these volcanic plumes, especially for pixels with large AAI values. For pixels with small AAI values and large effective cloud fractions, the retrieved cloud and scene pressures are most probably close to the cloud layer pressure.

\subsection{Saharan desert dust}

The Western Sahara is a main source of dust and mineral aerosols (Kaufman et al., 2005). The Saharan dust storms, which peak in June/July, are controlled by small-scale highwind events (De Graaf et al., 2005; Engelstaedter and Washington, 2007). We selected an event on 30 June 2010 based on GOME-2 AAI images and MODIS images.

Figure 14 shows the MODIS Terra image over the Sahara desert measured at 10:30-10:35 UTC on 30 June 2010 and the GOME-2 AAI and FRESCO cloud images. The dust plume is clearly visible over the Sahara desert around $20^{\circ} \mathrm{N}$ 


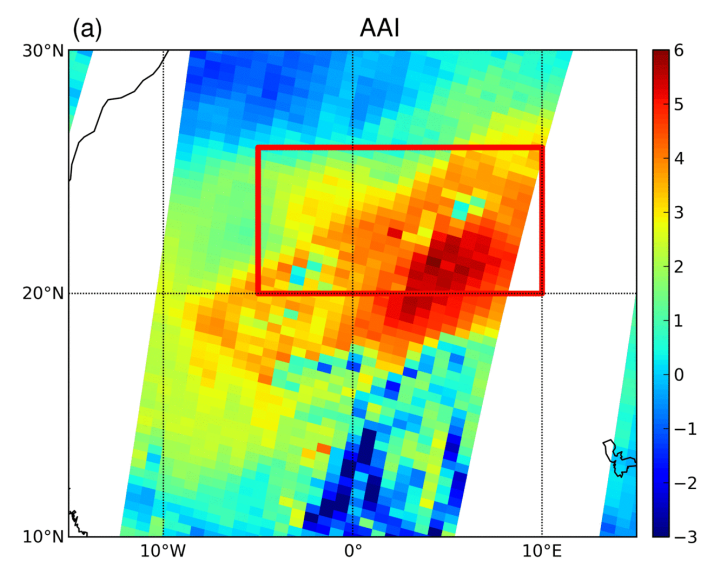

(b)
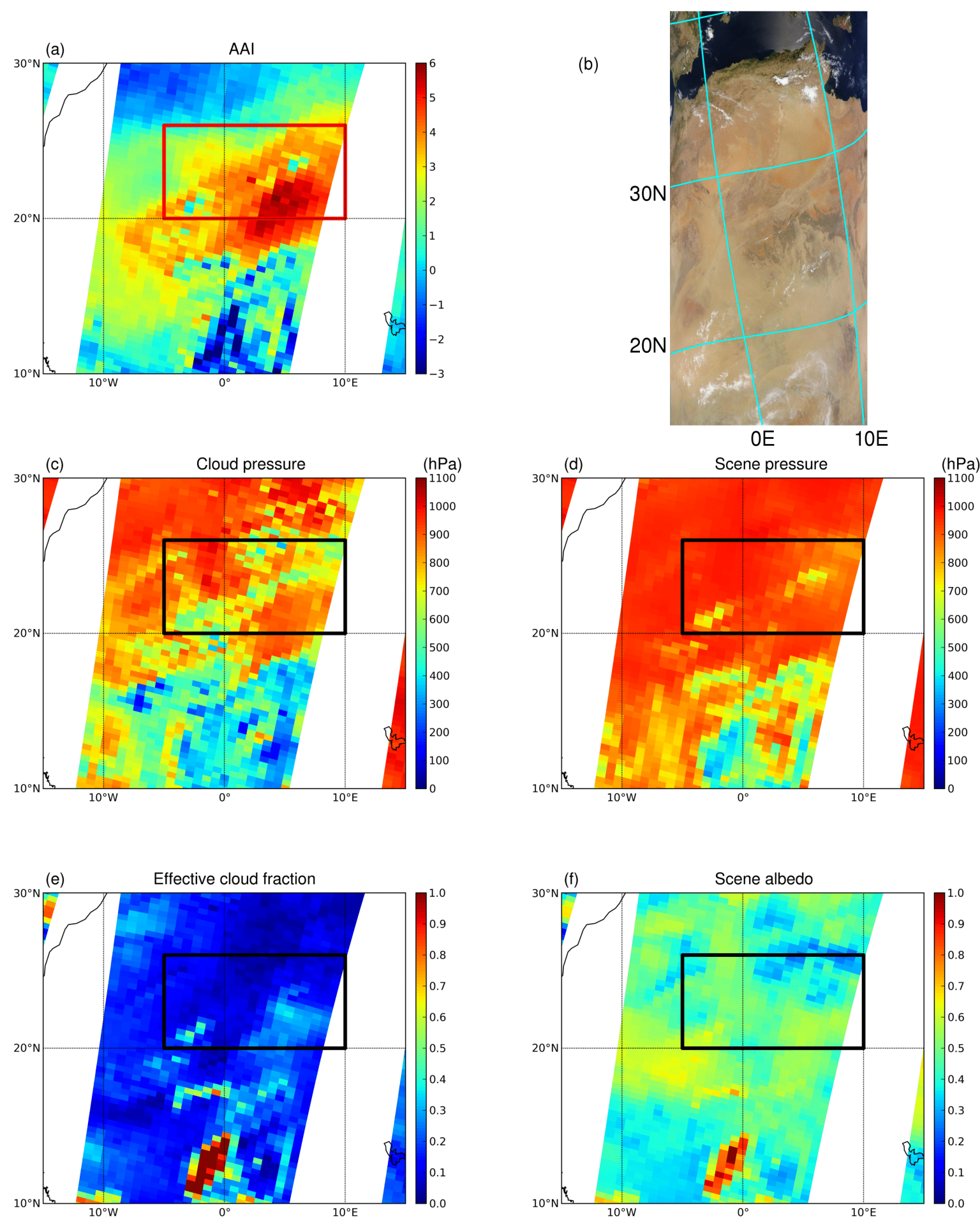

Fig. 14. (a) GOME-2 AAI image, (b) MODIS RGB image, (c) GOME-2 cloud pressure, (d) GOME-2 scene pressure, (e) GOME-2 effective cloud fraction, and (f) GOME-2 scene albedo for the Saharan desert dust event on 30 June 2010. The location of the plume is indicated with a box in the GOME-2 images. The plume in the box was measured around 09:45 UTC. The MODIS image was measured at 10:30 UTC. The MODIS image is downloaded from the MODIS Rapid Response System (http://rapidfire.sci.gsfc.nasa.gov/). 

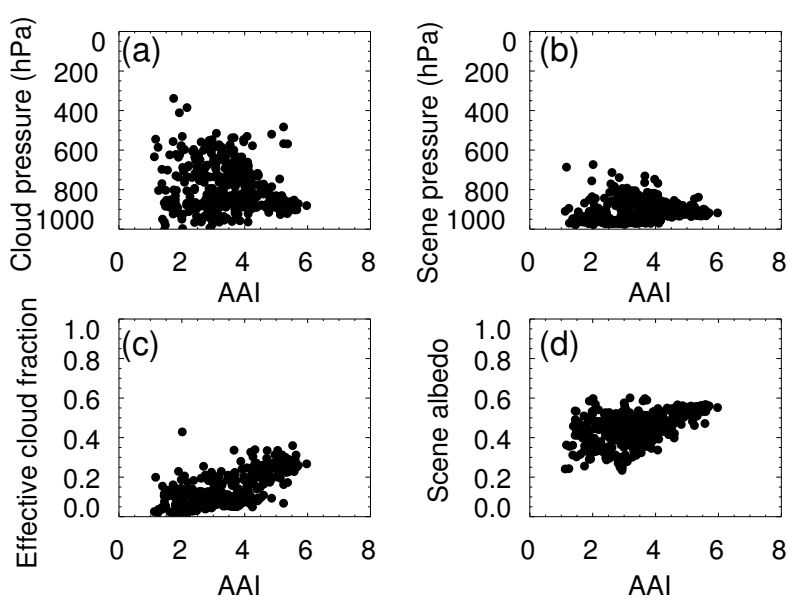

Fig. 15. Scatter plots of FRESCO (a) cloud pressure, (b) scene pressure, (c) effective cloud fraction, and (d) scene albedo versus absorbing aerosol index (AAI) from GOME-2 measurements of the Saharan desert dust event on 30 June 2010 around 09:45 UTC. The pixels used in the scatter plots are marked with a box in Fig. 14 in the region of $[20,26]^{\circ} \mathrm{N}$ and $[-5,10]^{\circ} \mathrm{E}$.

and $0-10^{\circ}$ E. There are only a few scattered clouds in the dust storm area. The dust plume as seen in the GOME-2 AAI image is associated with high AAI values up to 6 . The FRESCO effective cloud fraction image is in agreement with the MODIS image. For the areas with large AAI values, the effective cloud fractions are up to 0.3. Because we selected largely cloud free areas, FRESCO should retrieve aerosol pressure although it is called cloud pressure in the FRESCO products.

The scatter plots between FRESCO cloud results and AAI for the area of the dust plume between $[20,26]^{\circ} \mathrm{N},[-5$, $10]^{\circ} \mathrm{E}$ are shown in Fig. 15. It appears that most cloud pressures are higher than $500 \mathrm{hPa}$ and most scene pressures are higher than $800 \mathrm{hPa}$. For pixels with $\mathrm{AAI}<4$, some cloud and scene pressure values are close to $1000 \mathrm{hPa}$, probably because the cloud or aerosol layers are quite thin. The aerosols with AAI $>4$ are mainly at $850-900 \mathrm{hPa}$. In the plots of cloud pressure and scene pressure versus AAI, the cloud pressures tend to increase with AAI; the heights of the dust plumes are lower at larger AAI. The dust plumes are generated at the surface; therefore, it is not a surprise that the dust plumes are optically thicker at lower altitudes in the source region. Please note the contrast with the volcanic ash plumes (shown in Figs. 10 and 13) which tops are at similar heights, and have no significant decrease at large AAI. This is because the volcanic ash plumes are produced from a point source and are generally transported at a similar altitude above the surface.

The effective cloud fractions of the Saharan dust plumes increase with AAI (see Fig. 15), which indicates that the effective cloud (aerosol) fraction contains aerosol optical thick- ness information. It suggests that the dust plumes have variations in pressure and aerosol optical thickness.

Because the selected dust plume area is mainly cloud free, the scene albedo is a mixture of surface albedo and aerosol plume albedo. Since the surface albedo at the FRESCO wavelengths around $760 \mathrm{~nm}$ is large in the desert, the scene albedo may have a large contribution from the surface. The mean surface albedo around $760 \mathrm{~nm}$ in this area is 0.40 , with a minimum surface albedo of 0.2. Therefore, in Fig. 15 the scene albedo is larger than 0.2 , even if the cloud fraction is 0 .

\subsection{Biomass burning aerosols}

Biomass burning aerosol is absorbing in the UV and can be detected by the AAI. We will present a biomass burning aerosol case in South-West Africa on 6 August 2010. In Fig. 16, the MODIS fire count map at 09:20 UTC on $6 \mathrm{Au}-$ gust shows the fires as red spots. The smoke is caused by biomass burning on land and is transported westwards to the ocean above the marine stratocumulus cloud fields at about $900 \mathrm{hPa}$ (see Fig. 16). Between $[10,20]^{\circ} \mathrm{S}$ the GOME-2 AAI map shows a sharp boundary between land and ocean. The high AAI values are mainly over ocean in this region. The smoke over land in the cloud free region may not be detected due to the low surface albedo. Over ocean, the AAI is enhanced due to the reflection from the bright stratocumulus clouds below the smoke (see Figs. 4 and 8). As illustrated in Fig. 16, the FRESCO effective cloud fraction and scene albedo maps are in good agreement with the AAI map for this biomass burning aerosol event. The northeast part of the smoke plume is in a cloud free region over land and shows small effective cloud fraction values. The cloud pressure map is quite homogeneous for the smoke area. The low pressures at about $130 \mathrm{hPa}$ at $[15,20]^{\circ} \mathrm{S}$ next to the smoke area seem to be unrealistic, because there are almost no clouds or aerosols and the cloud fraction is very low. This artefact in the retrieved cloud pressure is a result of the low level of reflected light. However, for the same region, the scene pressure is retrieved correctly, namely close to the surface.

The scatter plots of Fig. 17 show the FRESCO cloud data versus the AAI data from GOME-2 measurements in the area of $[5,15]^{\circ} \mathrm{S}$ and $[10,15]^{\circ}$ E. Figure $17 \mathrm{c}$ and $\mathrm{d}$ show that the effective cloud fraction and scene albedo both increase with increasing AAI. When the effective cloud fraction reaches its maximum at AAI of 3, there occurs a decrease of the effective cloud fraction. This suggests that the effective cloud fractions are related to both cloud and aerosol optical thickness. The relatively large effective cloud fraction is mainly due to the clouds. Similarly, the scene albedo has contributions from clouds and aerosols, but it is mainly the bright cloud layer that leads to the large scene albedo values.

The FRESCO cloud pressures and scene pressures are comparable due to the large effective cloud fractions (see Fig. 17a and b). The smoke plume seems quite thin in the 


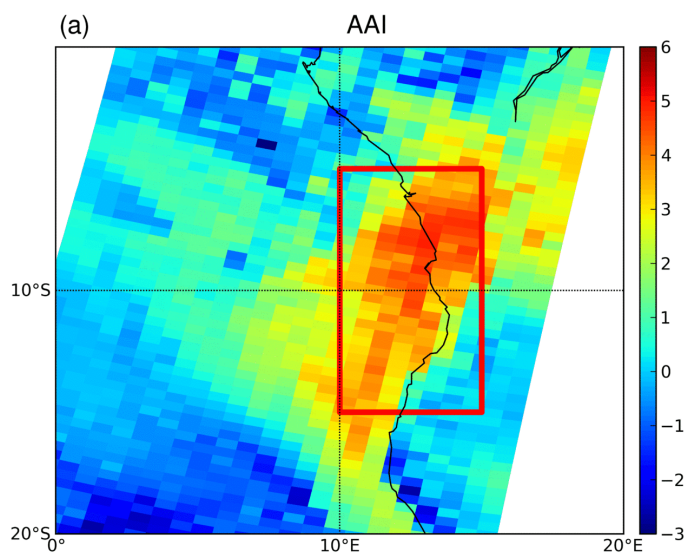

(b)
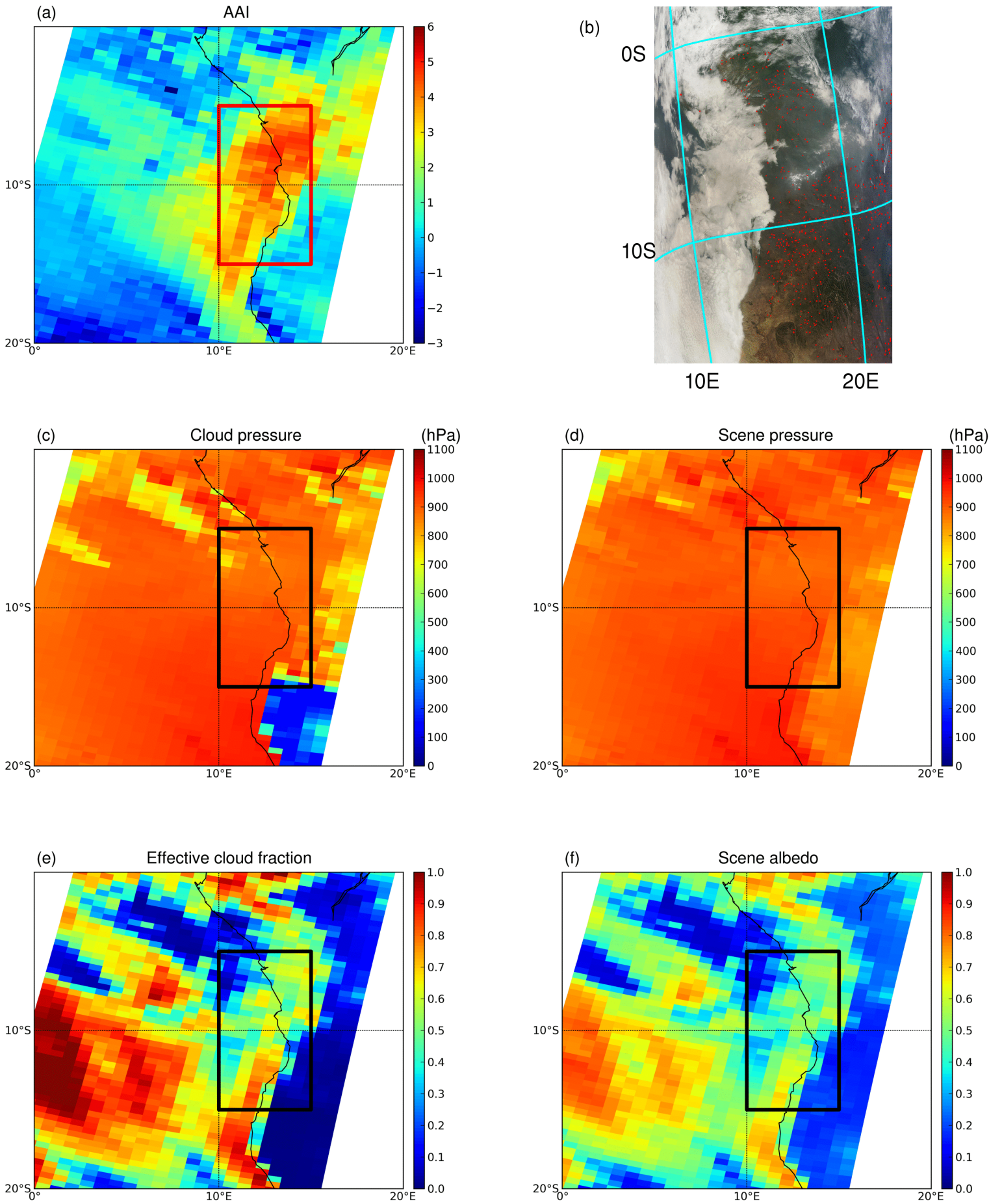

Fig. 16. (a) GOME-2 AAI image, (b) MODIS RGB image, (c) GOME-2 cloud pressure, (d) GOME-2 scene pressure, (e) GOME-2 effective cloud fraction, and (f) GOME-2 scene albedo for the biomass burning smoke event in South-West Africa on 6 August 2010. The location of the plume is indicated with a box in the GOME-2 images. The plume in the box was measured around 08:48 UTC. MODIS image was measured at 09:20 UTC. The red spots in MODIS images indicate fires. 

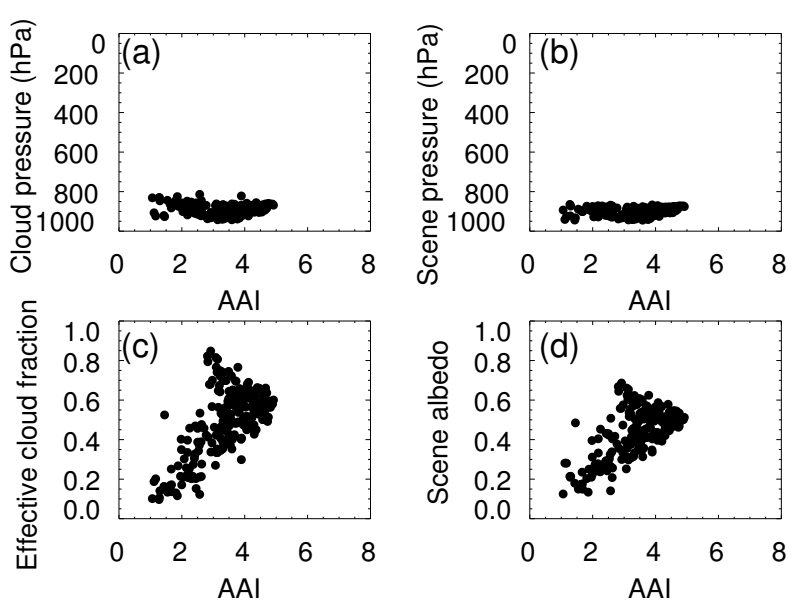

Fig. 17. Scatter plots of FRESCO (a) cloud pressure, (b) scene pressure, (c) effective cloud fraction, and (d) scene albedo versus absorbing aerosol index (AAI) from GOME-2 measurements of the biomass burning smoke event in South-West Africa on 6 August 2010 around 08:48 UTC. The pixels used in the scatter plots are marked with a box in Fig. 16 in the region of and $[5,15]^{\circ} \mathrm{S}$ and $[10,15]^{\circ} \mathrm{E}$.

MODIS image. According to our simulations of Sect. 3 the FRESCO cloud pressure and scene pressure are then close to the cloud layer pressure (see Figs. 1 and 2). This result agrees with the findings reported by Waquet et al. (2009), who analysed the aerosol and cloud heights from A-Train observations for a similar biomass burning aerosol case over low-level clouds over ocean. According to their case study, the CloudAerosol Lidar with Orthogonal polarisation (CALIOP) measured the aerosol layer to be located between 3 and $4 \mathrm{~km}$ and the cloud top height to be at about $1 \mathrm{~km}$. The aerosol optical thickness of 0.225 (at $865 \mathrm{~nm}$ ) was derived from the polarisation and Anisotropy of Reflectances for Atmospheric Sciences coupled with Observations from a Lidar (PARASOL) measurement. The cloud height retrieved from $\mathrm{O}_{2} \mathrm{~A}$ band measurements agreed well with the cloud height measured by CALIOP. On 6 August 2010, CALIOP measured aerosols at $4-5 \mathrm{~km}$ and a cloud layer at $1 \mathrm{~km}$ between $[6.5,12.5]^{\circ} \mathrm{S}$ and $[-0.6,-1.8]^{\circ} \mathrm{E}$ at about 13:52 UTC. It suggests that FRESCO does not retrieve aerosol height for this biomass burning event.

\subsection{Smoke from Russian wild fires}

The smoke from wild fires in Russia in August 2010 clearly shows up in the GOME-2 AAI maps and MODIS fire count map of 1 August 2010 (see Fig. 18). The smoke plume takes the form of an "S" shape in the MODIS image, right above the fire sources (red spots in the image). Based on the MODIS image, the smoke seems to be located above the clouds; for some places the surface is visible in the cloud free area. The MODIS image shows more clouds in the northern part of the plume than in the southern part. The shape of the plume appears to be the same in the AAI image as in the effective cloud fraction image. The cloud pressures are lower in the northern part $\left(60^{\circ} \mathrm{N}\right)$ and higher in the southern part of the plume (around $55^{\circ} \mathrm{N}$ ). However, it is difficult to distinguish the smoke pressure in the FRESCO cloud pressure and scene pressure maps. The maximum AAI value is 6 for this plume. According to Witte et al. (2011), OMI SSA values of 0.92 were observed during the wild fire period and the aerosol optical thickness was about 3 at $550 \mathrm{~nm}$ on 1 August 2010 measured by MODIS at $1^{\circ} \times 1^{\circ}$ around Moscow city.

The scatter plots of the FRESCO cloud products versus AAI in the area of $[52,60]^{\circ} \mathrm{N}$ and $[35,56]^{\circ} \mathrm{E}$ are shown in Fig. 19. The cloud pressure increases with AAI which indicates that the thickest plume is located at the lowest altitude. This is similar to the case of the dust plume in the Sahara desert. Here, the thickest smoke is measured close to the source of the fires. The cloud pressure and scene pressure values mostly vary between $400 \mathrm{hPa}$ and the surface, which indicates the variation of the smoke plume height. According to CALIOP measurements at 10:28-10:42 UTC on 1 August 2010 , between $[49,55]^{\circ} \mathrm{N}$ and $[35,38]^{\circ} \mathrm{E}$ the aerosol plume height is varying from the surface up to $5 \mathrm{~km}$. Although the CALIOP overpass is about $4 \mathrm{~h}$ later than the GOME- 2 measurements, it is confirmed that the aerosol height is in the same range as the FRESCO retrievals and quite variable. According to the simulations for BBA Case 2 shown in Fig. 4, if an aerosol layer is at $4-5 \mathrm{~km}$ and the AAI is 6 , the AOT could be about 2 at $340 \mathrm{~nm}$.

The effective cloud fraction and scene albedo both increase with AAI, which stresses the sensitivity of AAI to aerosol optical thickness, and shows that the FRESCO cloud product contains information about the smoke. The averaged surface albedo for this area is 0.255 ; therefore the smallest scene albedo is about 0.3 because of the contribution of clouds and/or aerosols. The cloud pressure and scene pressure contain information on aerosol pressure. However, it is difficult to tell whether the cloud pressure is close to the aerosol layer or close to the cloud layer. Since the smoke with the large AAI values should be above the clouds (otherwise the aerosols would not be visible), the cloud pressure or scene pressure can be used as a lower boundary of the aerosol height.

\section{Conclusions}

We have analysed GOME-2 FRESCO cloud retrievals for absorbing aerosol events. We first demonstrated with simulated FRESCO data that the FRESCO algorithm can retrieve aerosol height for optically thick absorbing aerosol cases. Next we presented four typical events with strongly absorbing aerosols: the Puyehue volcanic ash plume, a Saharan desert dust event, an African biomass burning smoke event, and a Russian wild fire smoke event. The analysis was based 

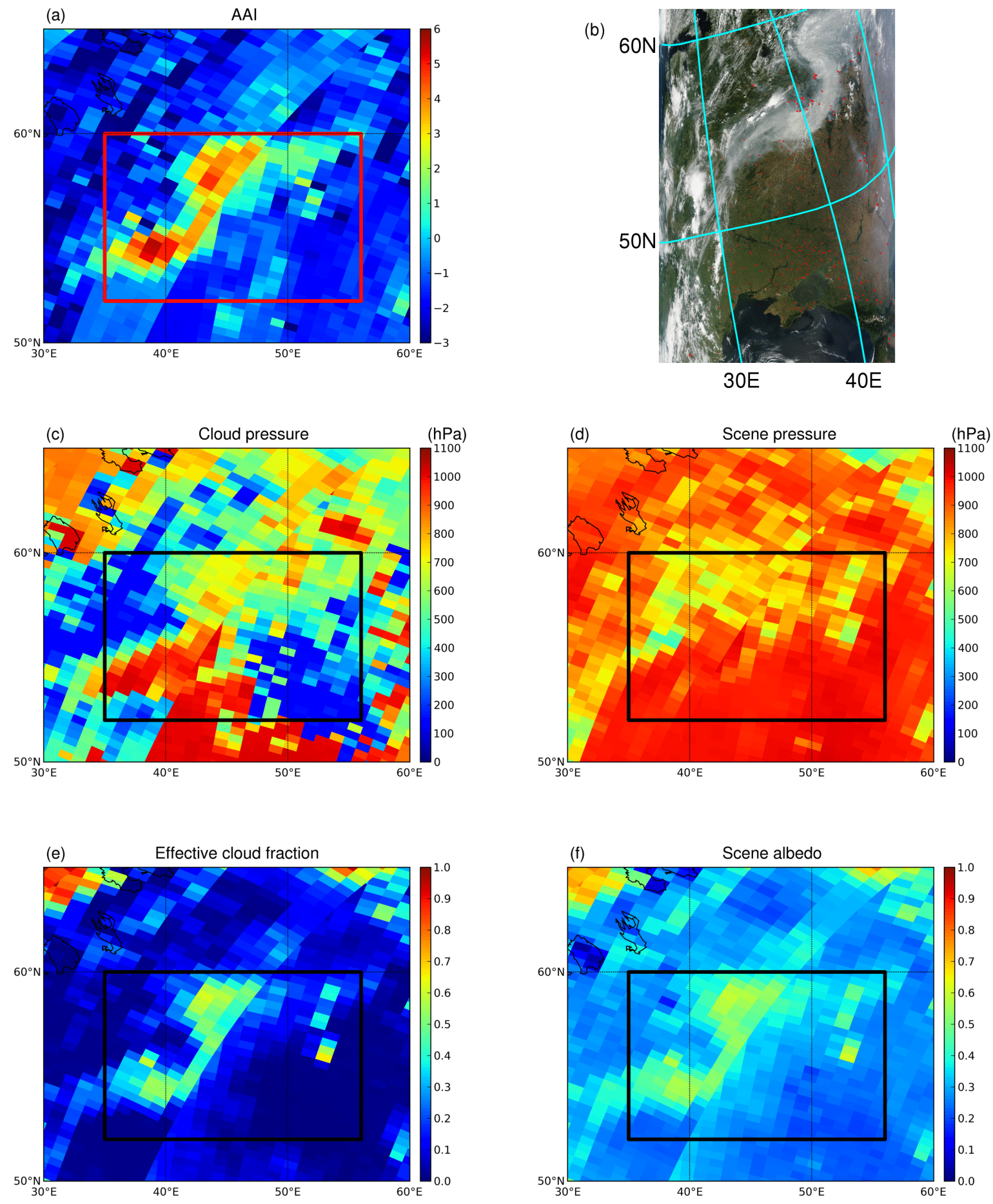

Fig. 18. (a) GOME-2 AAI image, (b) MODIS RGB image, (c) GOME-2 cloud pressure, (d) GOME-2 scene pressure, (e) GOME-2 effective cloud fraction, and (f) GOME-2 scene albedo for the smoke of Russian wild fires on 1 August 2010. The location of the plume is indicated with a box in the GOME-2 images. The plume in the box was measured around 06:50 UTC. The MODIS measurement is taken at 08:45 UTC. The red spots in the MODIS image indicate fires. 

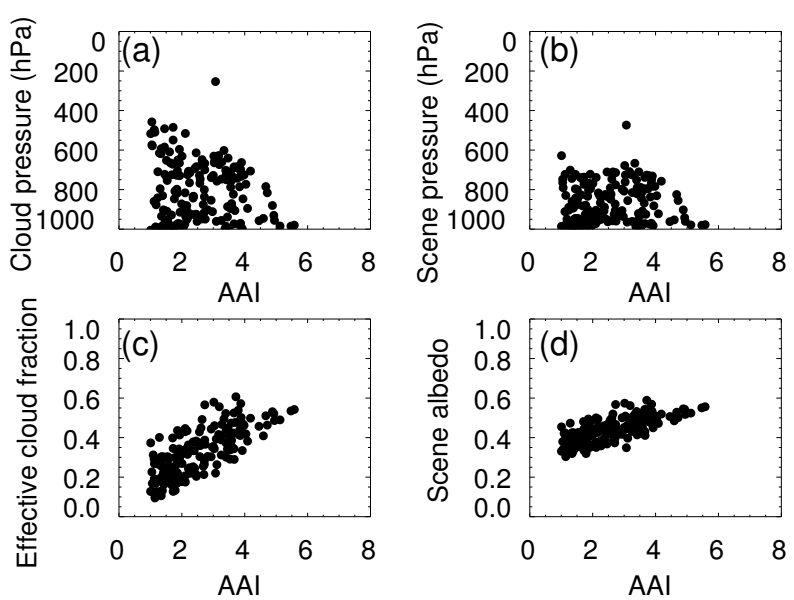

Fig. 19. Scatter plots of FRESCO (a) cloud pressure, (b) scene pressure, (c) effective cloud fraction, and (d) scene albedo versus absorbing aerosol index (AAI) from GOME-2 measurements of the Russian wild fire smoke event on 1 August 2010 around 06:50 UTC. The pixels used in the scatter plots are marked with a box in Fig. 18 in the region of $[52,60]^{\circ} \mathrm{N}$ and $[35,56]^{\circ} \mathrm{E}$.

on the sensitivity of the Absorbing Aerosol Index (AAI) to the aerosol optical thickness and aerosol layer height. If the AAI sensitivity is observed from the correlation of FRESCO cloud retrievals with the AAI, the FRESCO cloud retrievals contain aerosol information.

For the four events, effective cloud fraction and scene albedo both increase with AAI, resulting from the sensitivity of AAI to aerosol optical thickness. The FRESCO effective cloud fraction and scene albedo contain aerosol optical thickness information. If the pixel is cloud free, the effective cloud fraction takes up the role of effective aerosol fraction and the scene albedo is a mixture of the aerosol layer albedo and the surface albedo. The effective cloud fraction cannot be interpreted as cloud or aerosol optical thickness directly, but the correlation of effective cloud fraction and AAI indicates that aerosol information is present in the $\mathrm{O}_{2} \mathrm{~A}$ band measurements.

The FRESCO cloud pressure and scene pressure are more relevant quantities than the effective cloud fraction and scene albedo, because they give important information for aviation safety, in addition to the AAI. In cloudy situations, FRESCO can retrieve aerosol height when AOT $>3$ and $\mathrm{SSA}=0.86$ at $760 \mathrm{~nm}$ (biomass burning aerosol case). If the SSA is larger, an even larger AOT is needed. For optically thin aerosol layers above thick clouds, FRESCO can only retrieve the cloud height. In cloud free situations, FRESCO can also retrieve aerosol height for optically thinner absorbing aerosols, for example, AOT $>0.1$ and SSA $=0.92$ at $760 \mathrm{~nm}$ (desert dust case). Because of its wavelength dependence, the AOT at UV wavelengths can be a factor of 1.5-5 larger than the AOT at $760 \mathrm{~nm}$, depending on the aerosol model. For a typical biomass burning aerosol or dust event, if the AAI is larger than 1, FRESCO should be able to retrieve aerosol height in a cloud free scene. In reality, aerosols can be different from the aerosol models used in the simulations, so we could not give a quantitative relationship between the AAI values and FRESCO products except for some thresholds for the AOT.

According to our simulations, the scene pressure seems to be more reliable for the determination of aerosol height than the cloud pressure for extremely absorbing aerosol layers at high altitude. However, cases with AAI > 10 are rarely observed in GOME-2 measurements. In the events we analysed here the maximum AAI occurring was 8 . If, in the case of an aerosol plume, the cloud pressure shows a completely different behaviour than the scene pressure, and the AAI values are very large, then the scene pressure is likely more reliable than the cloud pressure.

Although the FRESCO algorithm is designed for clouds, for optically thick absorbing aerosols the effective cloud fraction and cloud height could be affected by aerosols. When using the FRESCO cloud product, this feature has to be taken into account. The cloud pressure and scene pressure can potentially provide useful aerosol height information, but the interpretation should be also based on AAI and cloud images.

Acknowledgements. We would like to thank Reinout Boers (KNMI) for helpful comments and suggestions on the manuscript. This work was supported by the Netherlands Space Office (NSO) as part of the SCIA-Visie project and by EUMETSAT as part of the O3M SAF CDOP-1 project. We would like to acknowledge EUMETSAT and the O3M SAF for GOME-2 data processing and data provision. The authors gratefully acknowledge the NOAA Air Resources Laboratory (ARL) for the provision of the HYSPLIT transport and dispersion model and READY website (http://www.arl.noaa.gov/ready.php) used in this publication. The MODIS team is acknowledged for providing the MODIS images. The MODIS RGB images were downloaded from LAADS Web (http://ladsweb.nascom.nasa.gov/browse_images/). The MODIS fire count maps were downloaded from the MODIS Rapid Response System http://rapidfire.sci.gsfc.nasa.gov/. The FRESCO and AAI data are available from the TEMIS website http://www.temis.nl. The authors wish to thank three anonymous reviewers for their detailed comments and suggestions, which have helped to considerably strengthen the paper.

Edited by: M. Van Roozendael

\section{References}

Anderson, G. P., Clough, S. A., Kneizys, F. X., Chetwynd, J. H., and Shettle, E. P.: AFGL atmospheric constituent profiles, Tech. Rep. AFGL-TR-86-0110, Air Force Geophys. Lab., Hanscom AFB, Mass, 1986.

Boesche, E., Stammes, P., Ruhtz, T., Preusker, R., and Fischer, $\mathrm{J} .:$ Effect of aerosol microphysical properties on polarization of skylight: sensitivity study and measurements, Appl. Optics, 45, 8790-8805, 2006. 
Boesche, E., Stammes, P., and Bennartz, R.: Aerosol influence on polarization and intensity in near-Infrared $\mathrm{O}_{2}$ and $\mathrm{CO}_{2}$ absorption bands observed from space, J. Quant. Spectrosc. Ra., 110, 3 , 223-239, doi:10.1016/j.jqsrt.2008.09.019, 2009.

Bovensmann, H., Burrows, J. P., Buchwitz, M., Frerick, J., Noël, S., Rozanov, V. V., Chance, K. V., and Goede, A. H. P.: SCIAMACHY - Mission objectives and measurement modes, J. Atmos. Sci., 56, 127-150, 1999.

de Graaf, M., Stammes, P., Torres, O., and Koelemeijer, R. B. A.: Absorbing Aerosol Index: Sensitivity analysis, application to GOME and comparison with TOMS, J. Geophys. Res., 110, D01201, doi:10.1029/2004JD005178, 2005.

de Graaf, M., Tilstra, L. G., Aben, I., and Stammes, P.: Satellite observations of the seasonal cycles of absorbing aerosols in Africa related to the monsoon rainfall; 1995-2008, Atmos. Environ., 44, 1274-1283, doi:10.1016/j.atmosenv.2009.12.038, 2010a.

de Graaf, M., Tuinder, O., and Tilstra, L. G.: O3MSAF Algorithm Theoretical Basis Document for ARS, O3MSAF/KNMI/ATBD/002, http://o3msaf.fmi.fi/docs/atbd/ Algorithm_Theoretical_Basis_Document_ARS_Apr_2010.pdf, $2010 b$.

de Graaf, M., Tilstra, L. G., Wang, P., and Stammes, P.: Retrieval of the aerosol direct radiative effect over clouds from spaceborne spectrometry, J. Geophys. Res., 117, D07207, doi:10.1029/2011JD017160, 2012.

de Haan, J. F., Bosma, P. B., and Hovenier, J. W.: The adding method for multiple scattering calculations of polarized light, Astron. Astrophys., 183, 371-391, 1987.

de Rooij, W. A. and van der Stap, C.: Expansion of Mie Scattering Matrices in Generalized Spherical Functions, Astron. Astrophys., 131, 237-248, 1984.

Dirksen, R. J., Boersma, K. F., de Laat, J., Stammes, P., van der Werf, G. R., Val Martin, M., and Kelder, H. M.: An aerosol boomerang: Rapid around-the-world transport of smoke from the December 2006 Australian forest fires observed from space, J. Geophys. Res., 114, D21201, doi:10.1029/2009JD012360, 2009.

Draxler, R. R. and Rolph, G. D.: HYSPLIT (HYbrid Single-Particle Lagrangian Integrated Trajectory) Model access via NOAA ARL READY Website (http://ready.arl.noaa.gov/HYSPLIT. php), NOAA Air Resources Laboratory, Silver Spring, MD, 2012.

Dubovik, O., Holben, B., Eck, T. E., Smirnov, A., Kaufman, Y. J., King, M. D., Tanre, D. and Slutsker, I.: Variability of absorption and optical properties of key aerosol types observed in worldwide locations, J. Atmos. Sci., 59, 590-608, 2002.

Dubuisson, P., Frouin, R., Dessailly, D., Duforêt, L., Léon, J.-F., Voss, K., and Antoine, D.: Estimating the altitude of aerosol plumes over the ocean from reflectance ratio measurements in the $\mathrm{O}_{2}$ A-band, Remote Sens. Environ., 113, 1899-1911, 2009.

Eckardt, F. D. and Kuring, N.: SeaWiFS identifies dust sources in the Namib Desert, Int. J. Remote Sens., 26, 4159-4167, doi:10.1080/01431160500113112, 2005.

Engelstaedter, S. and Washington, R.: Atmospheric controls on the annual cycle of North African dust, J. Geophys. Res., 112, D03103, doi:10.1029/2006JD007195, 2007.

Fromm, M., Tupper, A., Rosenfeld, D., Servranckx, R., and McRae, R.: Violent pyroconvective storm devastates Australia's capital and pollutes the stratosphere, Geophys. Res. Lett., 33, L05815, doi:10.1029/2005GL025161, 2006.
Grzegorski, M., Wenig, M., Platt, U., Stammes, P., Fournier, N., and Wagner, T.: The Heidelberg iterative cloud retrieval utilities (HICRU) and its application to GOME data, Atmos. Chem. Phys., 6, 4461-4476, doi:10.5194/acp-6-4461-2006, 2006.

Guan, H., Esswein, R., Lopez, J., Bergstrom, R., Warnock, A., Follette-Cook, M., Fromm, M., and Iraci, L. T.: A multidecadal history of biomass burning plume heights identified using aerosol index measurements, Atmos. Chem. Phys., 10, 64616469, doi:10.5194/acp-10-6461-2010, 2010.

Hansen, J. E. and Travis, L. D.: Light scattering in planetary atmospheres, Space Sci. Rev., 16, 527-610, doi:10.1007/BF00168069, 1974.

Herman, J. R., Bhartia, P. K., Torres, O., Hsu, C., Seftor, C., and Celarier, E.: Global distributions of UV-absorbing aerosols from Nimbus 7/TOMS data, J. Geophys. Res., 102, 16911-16922, doi:10.1029/96JD03680, 1997.

Jeong, M.-J. and Hsu, N. C.: Retrievals of aerosol single-scattering albedo and effective aerosol layer height for biomass-burning smoke: Synergy derived from A-Train sensors, Geophys. Res. Lett., 35, L24801, doi:10.1029/2008GL036279, 2008.

Jethva, H. and Torres, O.: Satellite-based evidence of wavelengthdependent aerosol absorption in biomass burning smoke inferred from Ozone Monitoring Instrument, Atmos. Chem. Phys., 11, 10541-10551, doi:10.5194/acp-11-10541-2011, 2011.

Jin, Z., Charlock, T. P., Smith Jr., W. L., and Rutledge, K.: A parameterization of ocean surface albedo, Geophys. Res. Lett., 31, L22301, doi:10.1029/2004GL021180, 2004.

Kaufman, Y. J., Koren, I., Remer, L. A., Tanré, D., Ginoux, P., and Fan, S.: Dust transport and deposition observed from the Terra-Moderate Resolution Imaging Spectroradiometer (MODIS) spacecraft over the Atlantic Ocean, J. Geophys. Res., 110, D10S12, doi:10.1029/2003JD004436, 2005.

Koelemeijer, R. B. A., Stammes, P., Hovenier, J. W., and de Haan, J. F.: A fast method for retrieval of cloud parameters using oxygen A band measurements from GOME, J. Geophys. Res., 106, 3475-3490, 2001.

Koelemeijer, R. B. A., de Haan, J. F., and Stammes, P.: A database of spectral surface reflectivity in the range 335-772 nm derived from 5.5 years of GOME observations, J. Geophys. Res., 108, D24070, doi:10.1029/2002JD002429, 2003.

Kokhanovsky, A. A., Rozanov, V. V., Nauss, T., Reudenbach, C., Daniel, J. S., Miller, H. L., and Burrows, J. P.: The semianalytical cloud retrieval algorithm for SCIAMACHY I. The validation, Atmos. Chem. Phys., 6, 1905-1911, doi:10.5194/acp-6-1905-2006, 2006.

Krijger, J. M., van Weele, M., Aben, I., and Frey, R.: Technical Note: The effect of sensor resolution on the number of cloud-free observations from space, Atmos. Chem. Phys., 7, 2881-2891, doi:10.5194/acp-7-2881-2007, 2007.

Loyola, D.: Automatic cloud analysis from polar-orbiting satellites using neural network and data fusion techniques, in: Proceedings of the IEEE International Geoscience and Remote Sensing Symposium, IGARSS'2004, Anchorage, 4, 2530-2534, 2004.

Munro, R., Eisinger, M., Anderson, C., Callies, J., Corpaccioli, E., Lang, R., Lefebvre, A., Livschitz, Y., and Albinana, A. P.: GOME-2 on MetOp, Proceeding of the 2006 EUMETSAT Meteorological Satellite Conference, Helsinki, Finland, 12-16 June 2006, EUMETSAT P. 48, 2006. 
Penning de Vries, M. and Wagner, T.: Modelled and measured effects of clouds on UV Aerosol Indices on a local, regional, and global scale, Atmos. Chem. Phys., 11, 12715-12735, doi:10.5194/acp-11-12715-2011, 2011.

Popp, C., Wang, P., Brunner, D., Stammes, P., Zhou, Y., and Grzegorski, M.: MERIS albedo climatology for FRESCO + $\mathrm{O}_{2}$ A-band cloud retrieval, Atmos. Meas. Tech., 4, 463-483, doi:10.5194/amt-4-463-2011, 2011.

Rolph, G. D.: Real-time Environmental Applications and Display sYstem (READY) Website (http://ready.arl.noaa.gov), NOAA Air Resources Laboratory, Silver Spring, MD, 2012.

Rothman, L. S., Gordon, I. E., Barbe, A., Benner, D. C., Bernath, P. F., Birk, M., Boudon, V., Brown, L. R., Campargue, A., Champion, J.-P., Chance, K., Coudert, L. H., Dana, V., Devi, V. M., Fally, S., Flaud, J.-M., Gamache, R. R., Goldman, A., Jacquemart, D., Kleiner, I., Lacome, N., Lafferty, W. J., Mandin, J.Y., Massie, S. T., Mikhailenko, S. N., Miller, C. E., MoazzenAhmadi, N., Naumenko, O. V., Nikitin, A. V., Orphal, J., Perevalov, V. I., Perrin, A., Predoi-Cross, A., Rinsland, C. P., Rotger, M., Šimečková, M., Smith, M. A. H., Sung, K., Tashkun, S. A., Tennyson, J., Toth, R. A., Vandaele, A. C., and Vander Auwera, J.: The HITRAN 2008 molecular spectroscopic database, J. Quant. Spectrosc. Radiat. Tansfer, 110, 533-572, 2009.

Sinyuk, A., Torres, O., and Dubovik, O.: Combined use of satellite and surface observations to infer the imaginary part of refractive index of Saharan dust, Geophys. Res. Lett., 30, 1081, doi:10.1029/2002GL016189, 2003.

Stammes, P.: Spectral radiance modeling in the UV-visible range, in: IRS 2000: Current Problems in Atmospheric Radiation, edited by: Smith, W. and Timofeyev, Y., A. Deepak, Hampton, Va., 385-388, 2001.

Stammes, P., Sneep, M., de Haan, J. F., Veefkind, J. P., Wang, P., and Levelt, P. F.: Effective cloud fractions from the Ozone Monitoring Instrument: Theoretical framework and validation, J. Geophys. Res., 113, D16S38, doi:10.1029/2007JD008820, 2008.

Tilstra, L. G., Tuinder, O. N. E., and Stammes, P.: GOME-2 Absorbing Aerosol Index: Statistical analysis, comparison to GOME1 and impact of instrument degradation, in: Proceedings of the 2010 EUMETSAT Meteorological Satellite Conference, EUMETSAT P. 57, ISBN 978-92-9110-089-7, 2010.
Torres, O., Bhartia, P. K., Herman, J. R., Ahmad, Z., and Gleason, J.: Derivation of aerosol properties from satellite measurements of backscattered ultraviolet radiation: theoretical basis, J. Geophys. Res., 103, p. 17099, doi:10.1029/98JD00900, 1998.

Torres, O., Tanskanen, A., Veihelmann, B., Ahn, C., Braak, R., Bhartia, P. K., Veefkind, P., and Levelt, P.: Aerosols and surface UV products from Ozone Monitoring Instrument observations: an overview, J. Geophys. Res., 112, D24S47, doi:10.1029/2007JD008809, 2007.

Torres, O., Jethva, H., and Bhartia, P. K.: Retrieval of aerosol optical depth above clouds from OMI observations: sensitivity analysis and case studies, J. Atmos. sci., 69, 1037-1053, 2012.

Wang, P. and Stammes, P.: FRESCO-GOME2 project, EUM/CO/06/1536/FM, final report, EUMETSAT, Darmstadt, 14 September, 2007.

Wang, P. and van der A, R.: Product Specification Document FRESCO, TEM/PSD2/003, http://www.temis.nl/docs/ PSD_FRESCO.pdf, 2011.

Wang, P., Stammes, P., van der A, R., Pinardi, G., and van Roozendael, M.: FRESCO+: an improved $\mathrm{O}_{2}$ A-band cloud retrieval algorithm for tropospheric trace gas retrievals, Atmos. Chem. Phys., 8, 6565-6576, doi:10.5194/acp-8-6565-2008, 2008.

Wang, P., Stammes, P., and Mueller, R.: Surface solar irradiance from SCIAMACHY measurements: algorithm and validation, Atmos. Meas. Tech., 4, 875-891, doi:10.5194/amt-4-875-2011, 2011.

Waquet, F., Riedi, J., Labonnote, L. C., and Goloub, P.: Aerosol remote sensing over clouds using A-Train observations, J. Atmos. Sci., 66, 2468-2480, doi:10.1175/2009JAS3026.1, 2009.

Witte, J. C., Douglass, A. R., da Silva, A., Torres, O., Levy, R., and Duncan, B. N.: NASA A-Train and Terra observations of the 2010 Russian wildfires, Atmos. Chem. Phys., 11, 9287-9301, doi:10.5194/acp-11-9287-2011, 2011.

Yu, H., Chin, M., Winker, D. M., Omar, A. H., Liu, Z., Kittaka, C., and Diehl T.: Global view of aerosol vertical distributions from CALIPSO lidar measurements and GOCART simulations: Regional and seasonal variations, J. Geophys. Res., 115, D00H30, doi:10.1029/2009JD013364, 2010. 